\title{
Non-Invasive Brain Stimulation in Dementia: A Complex Network Story
}

\author{
Lorenzo Pini $^{\mathrm{a}, \mathrm{b}}$ Rosa Manentic Maria Cotellic Francesca B. Pizzini ${ }^{\mathrm{d}}$ \\ Giovanni B. Frisoni ${ }^{a}$ e Michela Pievani $^{\text {a }}$ \\ a Laboratory Alzheimer's Neuroimaging \& Epidemiology, IRCCS Istituto Centro San Giovanni di Dio Fatebenefratelli, \\ Brescia, Italy; bepartment of Molecular and Translational Medicine, University of Brescia, Brescia, Italy;

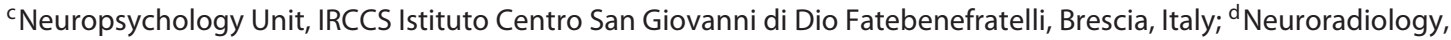 \\ Department of Diagnostics and Pathology, Verona University Hospital, Verona, Italy; ${ }^{~}$ University Hospitals and \\ University of Geneva, Geneva, Switzerland
}

\section{Keywords}

Non-invasive stimulation · Dementia · Functional

connectivity $\cdot$ Resting state networks

\begin{abstract}
Non-invasive brain stimulation (NIBS) is emerging as a promising rehabilitation tool for a number of neurodegenerative diseases. However, the therapeutic mechanisms of NIBS are not completely understood. In this review, we will summarize NIBS results in the context of brain imaging studies of functional connectivity and metabolites to gain insight into the possible mechanisms underlying recovery. We will briefly discuss how the clinical manifestations of common neurodegenerative disorders may be related with aberrant connectivity within large-scale neural networks. We will then focus on recent studies combining resting-state functional magnetic resonance imaging with NIBS to delineate how stimulation of different brain regions induce complex network modifications, both at the local and distal level. Moreover, we will review studies combining magnetic resonance spectroscopy and NIBS to investigate how microscale changes are related to modifications of large-scale networks. Finally, we will re-examine previous NIBS studies in dementia
\end{abstract}

๑ 2019 S. Karger AG, Basel in light of this network perspective. A better understanding of NIBS impact on the functionality of large-scale brain networks may be useful to design beneficial treatments for neurodegenerative disorders.

(c) 2019 S. Karger AG, Basel

\section{Introduction}

Dementia is a chronic syndrome characterized by a progressive decline in cognition, behavior, and everyday activities that affects mainly older people and, with the population aging at a fast rate worldwide, its burden is destined to increase dramatically [1]. To date, no pharmacological treatment is available to prevent or cure dementia, thus highlighting the urgent need for new, effective, therapeutic strategies.

In recent years, non-invasive brain stimulation (NIBS) techniques, such as transcranial magnetic stimulation (TMS) and transcranial direct current stimulation (tDCS) have been developed and are currently under investigation in patients with dementia [2]. During TMS, transient rapid-changing magnetic fields are used to induce secondary electric currents in the underlying corti-

\section{KARGER}

E-Mail karger@karger.com

www.karger.com/ndd
Michela Pievani, $\mathrm{PhD}$

Laboratory Alzheimer's Neuroimaging and Epidemiology

IRCCS Istituto Centro San Giovanni di Dio Fatebenefratelli

via Pilastroni 4, IT-25125 Brescia (Italy)

E-Mail mpievani@ fatebenefratelli.eu 
cal surface, which, in turn, trigger neuronal action potentials [3]. Single-pulse TMS is commonly employed to study brain functioning, while repetitive TMS (rTMS) is the preferred approach to induce long-lasting changes in brain activity. By contrast, during tDCS, a weak electrical current is directly applied to the scalp to modulate neuronal membrane potentials without directly inducing synchronized neuronal discharge [4]. Both rTMS and tDCS can have excitatory or inhibitory effects, depending on the frequency (rTMS) and the polarity (tDCS), respectively [5]. Low-frequency $(<1 \mathrm{~Hz}) \mathrm{rTMS}$ is thought to have inhibitory effects, high-frequency stimulation $(>5 \mathrm{~Hz})$ excitatory effects; tDCS induces neural hyperpolarization under the cathode and depolarization under the anode, respectively, reducing/increasing the responsiveness of the target neurons to the ongoing afferent brain activity $[6,7]$. Recently, theta-burst stimulation (TBS), a variant of TMS, has received increasing interest thanks to its ability to induce long-lasting changes just after a few minutes of application of burst of high frequency stimulation, delivered either as a continuous (cTBS) or intermittent (iTBS) train [8]. The former protocol is characterized as being "inhibitory" and the latter "excitatory," according to the changes produced in motor evoked potentials size [9].

Although preliminary evidence indicates promising effects of NIBS in neurodegenerative diseases [10, 11], there are still several barriers to the application of these techniques in the clinical practice. First, the mechanisms by which NIBS exerts its clinical effects are yet to be determined. Specifically, it is unclear how the transition of NIBS effects from the cellular to the mesoscopic, macroscopic, and behavioral levels occurs [12]. In the case of dementia, this issue is complicated by the presence of aging- and disease-related phenomena (e.g., atrophy, reduced intrinsic plasticity) that may importantly mitigate the impact of NIBS. Furthermore, NIBS after-effects are highly dependent on a variety of parameters (e.g., the localization of TMS coil or tDCS electrodes, intensity, and duration) [13], all aspects for which there is no consensus yet. Finally, NIBS is usually applied focusing on the behavioral effects but overlooking the possible underlying biological processes. However, it is now well established that the major dementias are linked to specific molecular pathologies and that these pathologies affect specific large-scale networks [14].

In the past 10 years, resting-state functional MRI (rsfMRI) identified neural networks associated with specific cognitive and motor-sensory functions, and the neurodegenerative disorders associated with a dysfunction of these networks (Fig. 1). Studies suggest that memory is sustained by two networks, the default mode network $(D M N)$ and the limbic network [15]. Neocortical networks such as the frontoparietal (FPN), visual, and language networks underlie executive, visuospatial, and language abilities, respectively [16]. Moreover, the so-called salience network (SN) is involved in social behavior, emotion regulation, and self-awareness [17].

There is increasing evidence that neurodegenerative diseases affect specific networks, leading to the hypothesis of "molecular nexopathy" models of disease progression (i.e., the conjunction mechanism between molecular pathology and neural network disruption) [18]. This assumption is supported by several studies reporting a close correspondence between network disruption, molecular disease, and clinical symptoms [14]. In typical late-onset Alzheimer's disease (AD), consistently with the core symptom (i.e., memory impairment), the $\mathrm{DMN}$ and the limbic network show selective vulnerability [19]. Conversely, early-onset $\mathrm{AD}$ variant preferentially affects neocortical functions such as language, executive and visuospatial abilities, showing aberrant connectivity in neocortical networks sustaining these functions [20]. Within the frontotemporal dementia spectrum, primary progressive aphasia (PPA), a disorder characterized by language impairment [21], shows disruption of the language network [22], while the behavioral variant of frontotemporal dementia (bvFTD), which is characterized by a range of behavioral disturbances [23], is associated with the disruption of the SN [24]. Similarly, posterior cortical atrophy, a condition characterized by predominant visuospatial dysfunctions [25] is associated with lower connectivity in the higher visual network [20]. Network abnormalities in Parkinson's disease (PD) and corticobasal syndrome (CBS), two disorders of the motor spectrum, seem to involve the cerebello-thalamo-cortical and sensorimotor networks, respectively $[14,26]$. While this evidence points to a clear correspondence between functional networks and syndrome-specific core symptoms, network dysfunction is not limited to a single circuit but generally involves several networks [17].

The disruption of large-scale neural networks might provide an intermediate link between pathology and clinical symptoms for neurodegenerative dementias. Therefore, brain stimulation of affected neural networks may offer a novel therapeutic strategy. To date, most of NIBS clinical interventions have focused on the effect of modulation on single brain areas, possibly overlooking more widespread effects of stimulation over distal areas or large-scale networks. This approach provides a fragment- 


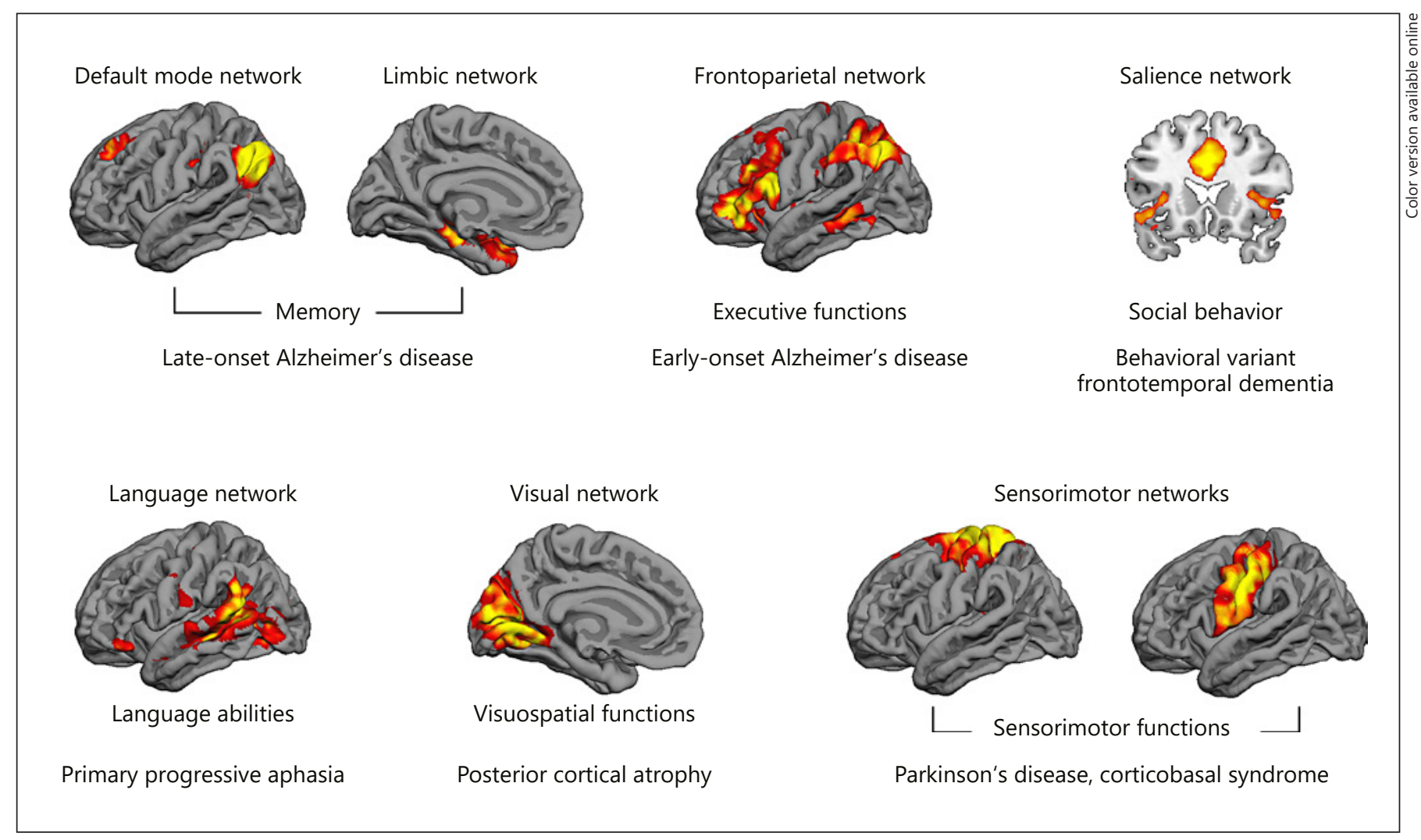

Fig. 1. Neural networks associated with specific cognitive and sensorimotor functions and the associated neurodegenerative disorders. Maps were extracted through independent component analysis from a sample of 20 healthy subjects.

ed view of NIBS effects and prevents a clear understanding of the NIBS mechanisms underlying cognitive improvement in dementia. Conversely, a "network perspective" would consider not only the effects in targeted brain regions but within areas integrated in complex, distributed, large-scale neural networks [27], and this approach may better capture the neural correlates of behavioral changes after stimulation.

This review aims to provide a network perspective on NIBS interventions for healthy individuals and patients with dementia. In the next paragraph, we will review studies combining NIBS with functional imaging in cognitively healthy adults, showing how NIBS induces both local and distal connectivity changes. Subsequently, we will investigate the possible mechanisms underlying NIBS effects by reviewing studies in healthy combining stimulation with proton magnetic resonance spectroscopy $\left({ }^{1} \mathrm{H}\right.$ MRS), a MRI modality that enables to measure the level of specific neurotransmitters and neurometabolites underlying neuronal communication. Finally, we will retro- spectively evaluate previous NIBS clinical applications in the most common neurodegenerative disorders in the light of the above considerations.

\section{Local and Distal Connectivity Effects of NIBS}

To date, several studies have combined NIBS with rsfMRI in young healthy subjects to investigate the modulatory effects of NIBS on brain networks (Table 1). Overall, these studies consistently reported that NIBS alters connectivity in the target brain region (local effect) but also in remote regions interconnected within the stimulated area (distal effect). These studies, reviewed below, are classified according to the target of stimulation (Fig. 2).

\section{Sensorimotor and Auditory Cortex}

Studies investigating NIBS effects over the sensorimotor cortex generally used the primary motor region (M1) as the target of stimulation, consistently showing in- 
Table 1. Non-invasive brain stimulation studies in healthy controls using rs-fMRI as outcome measure

\begin{tabular}{lllll}
\hline First author, year [Ref.] Sample & $\begin{array}{l}\text { NIBS } \\
\text { technique }\end{array}$ & Target site & $\begin{array}{l}\text { Stimulation } \\
\text { parameters and } \\
\text { design }\end{array}$ & $\begin{array}{l}\text { MRI scanner, } \\
\text { rs-fMRI } \\
\text { acquisition, } \\
\text { and analysis }\end{array}$ \\
\hline
\end{tabular}

Sensory-motor and auditory cortex

Amadi, $2014[28] \quad 11$ young tDCS
Active: L M1

Reference: R supraorbital
(1 $\mathrm{mA})$, atDCS,

ctDCS, and sham carried out 1 week apart
One 10-min session

3T, offline, Increased FC within the DMN ICA, seed ROI and motor network and increased inter-hemispheric connectivity between target site and $\mathrm{R} M 1$ and between $\mathrm{L}$ and R SMA after ctDCS; no effects after atDCS

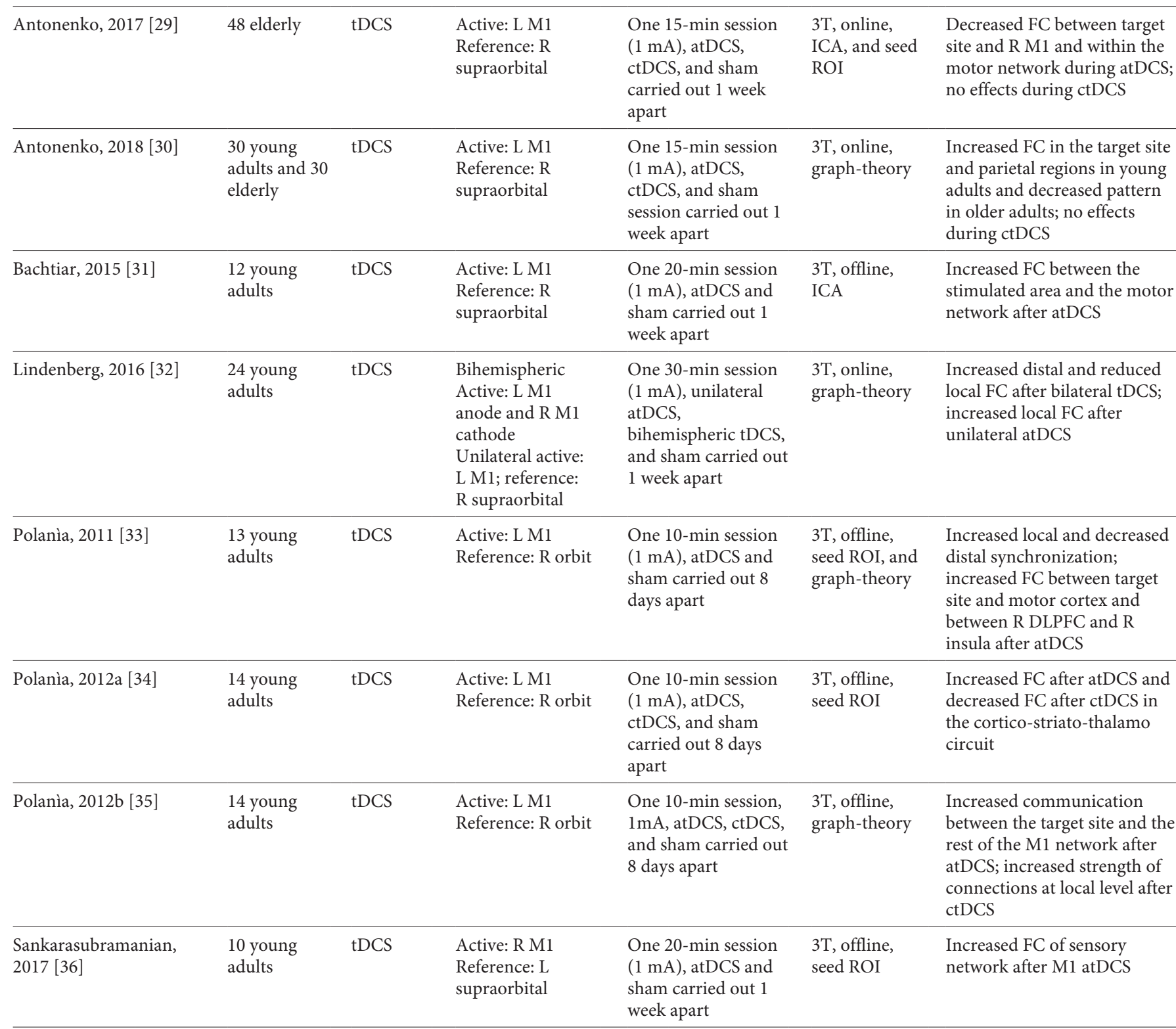


Table 1 (continued)

\begin{tabular}{|c|c|c|c|c|c|c|}
\hline First author, year [Ref.] & Sample & $\begin{array}{l}\text { NIBS } \\
\text { technique }\end{array}$ & Target site & $\begin{array}{l}\text { Stimulation } \\
\text { parameters and } \\
\text { design }\end{array}$ & $\begin{array}{l}\text { MRI scanner, } \\
\text { rs-fMRI } \\
\text { acquisition, } \\
\text { and analysis }\end{array}$ & Main results \\
\hline Sehm, 2012 [37] & $\begin{array}{l}12 \text { young } \\
\text { adults }\end{array}$ & $\mathrm{tDCS}$ & $\begin{array}{l}\text { Bihemispheric } \\
\text { Active: R M1 } \\
\text { anode and L M1 } \\
\text { cathode } \\
\text { Unilateral Active: } \\
\text { R M1; } \\
\text { Reference: L orbit }\end{array}$ & $\begin{array}{l}\text { One } 20 \text {-min session } \\
(1 \mathrm{~mA}) \text {, unilateral } \\
\text { atDCS, bihemisheric } \\
\text { tDCS, and sham } \\
\text { carried out } 1 \text { week } \\
\text { apart }\end{array}$ & $\begin{array}{l}\text { 3T, offline and } \\
\text { online, graph- } \\
\text { theory }\end{array}$ & $\begin{array}{l}\text { Widespread increased } \\
\text { functional coupling both } \\
\text { during and after unilateral } \\
\text { atDCS and bilateral tDCS }\end{array}$ \\
\hline Sehm, 2013 [38] & $\begin{array}{l}12 \text { young } \\
\text { adults }\end{array}$ & $\mathrm{tDCS}$ & $\begin{array}{l}\text { Bihemispheric } \\
\text { Active: R M1 } \\
\text { anode and L M1 } \\
\text { cathode } \\
\text { Unilateral Active: } \\
\text { R M1 } \\
\text { Reference: L orbit }\end{array}$ & $\begin{array}{l}\text { One } 20 \text {-min session } \\
(1 \mathrm{~mA}) \text {, unilateral } \\
\text { atDCS, } \\
\text { bihemispheric tDCS, } \\
\text { and sham carried out } \\
1 \text { week apart }\end{array}$ & $\begin{array}{l}\text { 3T, offline and } \\
\text { online, seed } \\
\text { ROI }\end{array}$ & $\begin{array}{l}\text { Online: reduced FC during } \\
\text { both unilateral atDCS and } \\
\text { bilateral atDCS; offline: } \\
\text { increased FC only after } \\
\text { bilateral tDCS }\end{array}$ \\
\hline $\begin{array}{l}\text { Watanabe, } 2014 \\
{[40]}\end{array}$ & $\begin{array}{l}6 \text { young } \\
\text { adults }\end{array}$ & TMS & Active: L M1 & $\begin{array}{l}\text { One } 30 \text {-min QPS } \\
\text { session, excitatory } \\
(200 \mathrm{~Hz}) \text { and } \\
\text { inhibitory }(20 \mathrm{~Hz}) \\
\text { carried out } 1 \text { week } \\
\text { apart }\end{array}$ & $3 \mathrm{~T}$, seed ROI & $\begin{array}{l}\text { Reduced FC correlation with } \\
\text { target site after excitatory } \\
\text { TMS; increased FC correlation } \\
\text { with target site after inhibitory } \\
\text { TMS }\end{array}$ \\
\hline Andoh, 2015 [41] & $\begin{array}{l}17 \text { young } \\
\text { adults }\end{array}$ & TBS & $\begin{array}{l}\text { Active: R HGal } \\
\text { Active: L HGal } \\
\text { Control: vertex }\end{array}$ & $\begin{array}{l}\text { One } 50-\mathrm{Hz} \text { session } \\
\text { ( } 70-80 \% \text { ATM), R } \\
\text { HGal cTBS, L HGal } \\
\text { cTBS, and vertex } \\
\text { cTBS carried out on } \\
3 \text { separate days }\end{array}$ & $\begin{array}{l}\text { 3T, ICA, and } \\
\text { seed ROI }\end{array}$ & $\begin{array}{l}\text { Reduced FC in auditory and } \\
\text { motor networks after R HGal } \\
\text { cTBS. Reduced FC in the } \\
\text { somatosensory and increased } \\
\text { FC in the auditory after vertex } \\
\text { cTBS }\end{array}$ \\
\hline \multicolumn{7}{|l|}{ Frontal cortex } \\
\hline Keeser, 2011 [43] & $\begin{array}{l}13 \text { young } \\
\text { adults }\end{array}$ & $\mathrm{tDCS}$ & $\begin{array}{l}\text { Active: L DLPFC } \\
\text { Reference: } \mathrm{R} \\
\text { supraorbital }\end{array}$ & $\begin{array}{l}\text { One } 20 \text {-min session } \\
(2 \mathrm{~mA}) \text {, atDCS, and } \\
\text { sham carried out } 1 \\
\text { week apart }\end{array}$ & $\begin{array}{l}\text { 3T, offline, } \\
\text { ICA }\end{array}$ & $\begin{array}{l}\text { Increased FC within DMN } \\
\text { and FPN after atDCS }\end{array}$ \\
\hline Meinzer, 2012 [44] & $\begin{array}{l}20 \text { young } \\
\text { adults }\end{array}$ & $\mathrm{tDCS}$ & $\begin{array}{l}\text { Active: L IFG } \\
\text { Reference: R } \\
\text { supraorbital }\end{array}$ & $\begin{array}{l}\text { One } 17 \text {-min session } \\
(1 \mathrm{~mA}) \text {, atDCS and } \\
\text { sham carried out } 1 \\
\text { week apart }\end{array}$ & $\begin{array}{l}\text { 3T, online, } \\
\text { graph-theory }\end{array}$ & $\begin{array}{l}\text { Increased connectivity in the } \\
\text { stimulated site and in hubs } \\
\text { overlapping with language } \\
\text { network after atDCS }\end{array}$ \\
\hline Meinzer, 2013 [45] & 20 elderly & tDCS & $\begin{array}{l}\text { Active: L IFG } \\
\text { Reference: R } \\
\text { supraorbital }\end{array}$ & $\begin{array}{l}\text { One } 20 \text {-min session } \\
(1 \mathrm{~mA}) \text {, atDCS and } \\
\text { sham carried out } 1 \\
\text { week apart }\end{array}$ & $\begin{array}{l}\text { 3T, online, } \\
\text { graph-theory }\end{array}$ & $\begin{array}{l}\text { Increased connectivity in } \\
\text { posterior-DMN and decreased } \\
\text { connectivity in } \\
\text { frontotemporal (showing } \\
\text { baseline hypoconnectivity and } \\
\text { hyperconnectivity, } \\
\text { respectively) after atDCS } \\
\text { "normalization" effect) }\end{array}$ \\
\hline
\end{tabular}


Table 1 (continued)

\begin{tabular}{|c|c|c|c|c|c|c|}
\hline First author, year [Ref.] & Sample & $\begin{array}{l}\text { NIBS } \\
\text { technique }\end{array}$ & Target site & $\begin{array}{l}\text { Stimulation } \\
\text { parameters and } \\
\text { design }\end{array}$ & $\begin{array}{l}\text { MRI scanner, } \\
\text { rs-fMRI } \\
\text { acquisition, } \\
\text { and analysis }\end{array}$ & Main results \\
\hline Park, 2013 [46] & $\begin{array}{l}39 \text { young } \\
\text { adults }\end{array}$ & $\mathrm{tDCS}$ & $\begin{array}{l}\text { Active: L DLPFC } \\
\text { Reference: } \mathrm{R} \\
\text { supraorbital }\end{array}$ & $\begin{array}{l}\text { One } 20 \text {-min session } \\
(1 \mathrm{~mA}) \text {, atDCS or } \\
\text { sham }\end{array}$ & $\begin{array}{l}\text { 3T, offline, } \\
\text { seed ROI }\end{array}$ & $\begin{array}{l}\text { Increased FC between L } \\
\text { DLPFC and frontal, temporal } \\
\text { and subcortical regions of } \\
\text { right hemisphere and } \\
\text { decreased in regions around } \\
\text { stimulation site }\end{array}$ \\
\hline Pena-Gomez, 2012 [47] & $\begin{array}{l}10 \text { young } \\
\text { adults }\end{array}$ & $\mathrm{tDCS}$ & $\begin{array}{l}\text { Active: } \mathrm{L} \text { and } \mathrm{R} \\
\text { DLPFC } \\
\text { Reference: } \mathrm{R} \text { and } \mathrm{L} \\
\text { supraorbital }\end{array}$ & $\begin{array}{l}\text { Two } 20 \text {-min session } \\
(2 \mathrm{~mA}), \mathrm{L} \text { atDCS, } \mathrm{R} \\
\text { atDCS, and sham } \\
\text { carried out } 1 \text { month } \\
\text { apart (1st session: } \\
\text { sham and L atDCS; } \\
\text { 2nd session: sham } \\
\text { and R atDCS) }\end{array}$ & $\begin{array}{l}\text { 3T, offline, } \\
\text { ICA }\end{array}$ & $\begin{array}{l}\text { Increased FC within FPN } \\
\text { hubs and decreased FC within } \\
\text { posterior and anterior DMN } \\
\text { hubs after either L or R atDCS }\end{array}$ \\
\hline Wörsching, 2017 [48] & $\begin{array}{l}20 \text { young } \\
\text { adults }\end{array}$ & $\mathrm{tDCS}$ & $\begin{array}{l}\text { Bihemispheric } \\
\text { Active: R DLPFC } \\
\text { anode and L } \\
\text { DLPFC cathode }\end{array}$ & $\begin{array}{l}\text { One } 20 \text {-min session } \\
(2 \mathrm{~mA}) \\
\text { bihemispheric tDCS } \\
\text { or sham }\end{array}$ & $\begin{array}{l}\text { 3T, offline and } \\
\text { online, ICA }\end{array}$ & $\begin{array}{l}\text { Mixed (increased/decreased) } \\
\text { FC changes within the DMN } \\
\text { and bilateral FPN after } \\
\text { bihemispheric tDCS }\end{array}$ \\
\hline Bilek, 2013 [49] & $\begin{array}{l}39 \text { young } \\
\text { adults }\end{array}$ & TMS & Active: R DLPFC & $\begin{array}{l}\text { One } 5-\mathrm{Hz} \text { session } \\
\text { ( } 90 \% \text { ATM), } \\
\text { excitatory and sham } \\
\text { carried out } 1 \text { week } \\
\text { apart }\end{array}$ & $3 \mathrm{~T}$, seed ROI & $\begin{array}{l}\text { No effect on resting state } \\
\text { connectivity }\end{array}$ \\
\hline Gratton, 2013 [52] & $\begin{array}{l}27 \text { young } \\
\text { adults }\end{array}$ & TBS & $\begin{array}{l}\text { Active: L DLPFC } \\
\text { Active: L aI/fO } \\
\text { Control: L S1 }\end{array}$ & $\begin{array}{l}\text { One } 50-\mathrm{Hz} \text { session, } \\
\text { ( } 80 \% \text { ATM), } 1 \\
\text { DLPFC cTBS, } 1 \text { aI/ } \\
\text { fOcTBSand } 1 \mathrm{~S} 1 \\
\text { cTBS carried out on } \\
3 \text { separate days }\end{array}$ & $3 \mathrm{~T}$, seed ROI & $\begin{array}{l}\text { Increased FC within and } \\
\text { between cognitive networks } \\
\text { (FPN and salience) }\end{array}$ \\
\hline $\begin{array}{l}\text { Iwabuchi, } 2017 \\
\text { [53] }\end{array}$ & $\begin{array}{l}28 \text { young } \\
\text { adults }\end{array}$ & TBS & Target: L DLPFC & $\begin{array}{l}\text { One } 50-\mathrm{Hz} \text { session } \\
(80 \% \text { ATM), iTBS } \\
\text { and sham carried out } \\
4 \text { days apart }\end{array}$ & 3T, GCA & $\begin{array}{l}\text { Reduced frontoinsular } \\
\text { connectivity }\end{array}$ \\
\hline $\begin{array}{l}\text { Mastropasqua, } \\
2014 \text { [54] }\end{array}$ & $\begin{array}{l}36 \text { young } \\
\text { adults }\end{array}$ & TBS & Active: R DLPFC & $\begin{array}{l}\text { One } 50-\mathrm{Hz} \text { session } \\
\text { ( } 80 \% \text { ATM), cTBS or } \\
\text { sham }\end{array}$ & 3T, seed ROI & $\begin{array}{l}\text { Decreased FC correlation } \\
\text { between stimulated site and } \mathrm{R} \\
\text { parietal cortex }\end{array}$ \\
\hline
\end{tabular}


Table 1 (continued)

\begin{tabular}{|c|c|c|c|c|c|c|}
\hline First author, year [Ref.] & Sample & $\begin{array}{l}\text { NIBS } \\
\text { technique }\end{array}$ & Target site & $\begin{array}{l}\text { Stimulation } \\
\text { parameters and } \\
\text { design }\end{array}$ & $\begin{array}{l}\text { MRI scanner, } \\
\text { rs-fMRI } \\
\text { acquisition, } \\
\text { and analysis }\end{array}$ & Main results \\
\hline
\end{tabular}

Temporoparietal cortex Antonenko, 2018 [55]
20 young tDCS adults and 20 elderly
Active: $\mathrm{R}$ temporoparietal Reference: L supraorbital
Three 20-min session (1 mA), atDCS or sham
3T, offline, ICA, and seed ROI
Increased FC between stimulated site and DMN and increased FC within DMN associated with better memory recall performance in both young and elderly

\begin{tabular}{|c|c|c|c|c|c|c|}
\hline Callan, 2016 [56] & $\begin{array}{l}28 \text { young } \\
\text { adults }\end{array}$ & $\mathrm{tDCS}$ & $\begin{array}{l}\text { Active: R parietal } \\
\text { Reference: L } \\
\text { shoulder }\end{array}$ & $\begin{array}{l}\text { One } 30 \text {-min session } \\
(1 \mathrm{~mA}) \text {, atDCS or } \\
\text { sham }\end{array}$ & $\begin{array}{l}\text { 3T, offline and } \\
\text { online, fALLF }\end{array}$ & $\begin{array}{l}\text { Increased resting state activity } \\
\text { in the precuneus after atDCS }\end{array}$ \\
\hline $\begin{array}{l}\text { Clemens, } 2014 \\
\text { [57] }\end{array}$ & $\begin{array}{l}11 \text { young } \\
\text { adults }\end{array}$ & $\mathrm{tDCS}$ & $\begin{array}{l}\text { Active: } \mathrm{R} \text { angular } \\
\text { gyrus } \\
\text { Reference: } \mathrm{L} \\
\text { supraorbital }\end{array}$ & $\begin{array}{l}\text { One } 20 \text {-min session } \\
(2 \mathrm{~mA}) \text {, atDCS }\end{array}$ & $\begin{array}{l}\text { 3T, offline, } \\
\text { ICA }\end{array}$ & $\begin{array}{l}\text { Increased FC within anterior- } \\
\text { DMN, cerebellar, task positive } \\
\text { (DAN), sensorimotor, } \\
\text { executive, and visual } \\
\text { networks, while decreased FC } \\
\text { within posterior-DMN and R } \\
\text { frontoparietal networks after } \\
\text { atDCS }\end{array}$ \\
\hline
\end{tabular}

\begin{tabular}{|c|c|c|c|c|c|}
\hline Hunter, 2015 [58] & $\begin{array}{l}11 \text { young } \\
\text { adults }\end{array}$ & tDCS & $\begin{array}{l}\text { Active: R superior } \\
\text { parietal } \\
\text { Reference: L upper } \\
\text { arm }\end{array}$ & $\begin{array}{l}\text { One } 30 \text {-min session } \\
(2 \mathrm{~mA}) \text {, atDCS }\end{array}$ & $\begin{array}{l}\text { 3T, offline, } \\
\text { ICA }\end{array}$ \\
\hline
\end{tabular}

\begin{tabular}{|c|c|c|c|c|c|c|}
\hline Möller, 2017 [59] & $\begin{array}{l}60 \text { young } \\
\text { adults }\end{array}$ & $\mathrm{tDCS}$ & $\begin{array}{l}\text { Bihemispheric } \\
\text { Active: B frontal; } \\
\text { reference: B } \\
\text { occipital or B } \\
\text { supraorbital } \\
\text { Bihemispheric } \\
\text { Active: B parietal; } \\
\text { reference: B } \\
\text { occipital }\end{array}$ & $\begin{array}{l}\text { Five } 25 \text {-min sessions } \\
(1 \mathrm{~mA}) \text {, bilateral } \\
\text { frontal atDCS or } \\
\text { bilateral parietal } \\
\text { atDCS or sham }\end{array}$ & $\begin{array}{l}3 \mathrm{~T} \text {, offline, } \\
\text { voxel-to-voxel }\end{array}$ & $\begin{array}{l}\text { Divergent modulation of FPN } \\
\text { after bilateral atDCS and } \\
\text { atDCS }\end{array}$ \\
\hline Eldaief, 2011 [60] & $\begin{array}{l}25 \text { young } \\
\text { adults }\end{array}$ & TMS & $\begin{array}{l}\text { Active: L IPL } \\
\text { (DMN hub) }\end{array}$ & $\begin{array}{l}\text { One } 20-\mathrm{Hz} \text { or } 1-\mathrm{Hz} \\
\text { session }(110 \% \\
\text { ATM), excitatory } \\
\text { and inhibitory } \\
\text { carried out } 1 \text { week } \\
\text { apart }\end{array}$ & $3 \mathrm{~T}$, seed ROI & $\begin{array}{l}20 \mathrm{~Hz} \text { reduced FC between } \\
\text { target and DMN ROIs; } 1 \mathrm{~Hz} \\
\text { increased FC in DMN ROIs } \\
\text { and between target and } \\
\text { bilateral hippocampus }\end{array}$ \\
\hline Mancini, 2017 [61] & $\begin{array}{l}15 \text { young } \\
\text { adults }\end{array}$ & TBS & Active: precuneus & $\begin{array}{l}\text { One } 50-\mathrm{Hz} \text { session } \\
(80 \% \text { ATM }) \text {, cTBS } \\
\text { and sham carried out } \\
1 \text { day apart }\end{array}$ & $\begin{array}{l}\text { 3T, graph- } \\
\text { theory }\end{array}$ & $\begin{array}{l}\text { Distal effect in the temporal } \\
\text { pole after cTBS: reduction of } \\
\text { its functional connectivity }\end{array}$ \\
\hline
\end{tabular}

Cerebellum

Halko, 2014 [62]
Increased FC in motor, FPN, $\mathrm{SN}$, and cerebellar networks, while decreased FC in the ACC and basal ganglia networks after atDCS; no DMN effects

after bilateral atDCS and atDCS

\begin{tabular}{|c|c|}
\hline $\begin{array}{l}\text { Active: R lateral } \\
\text { cerebellum (DMN } \\
\text { hub) } \\
\text { Active: midline } \\
\text { cerebellum (non } \\
\text { DMN hub) }\end{array}$ & $\begin{array}{l}\text { One } 50-\mathrm{Hz} \text { session } \\
\text { (100\% ATM), lateral } \\
\text { cerebellum iTBS, } \\
\text { midline cerebellar } \\
\text { iTBS, and sham } \\
\text { carried out at least } 2 \\
\text { days apart }\end{array}$ \\
\hline
\end{tabular}

Increased FC of cerebral cortical DMN after stimulation of the lateral cerebellum

Increased FC of dorsal attention network after stimulation of the midline cerebellum 
Table 1 (continued)

\begin{tabular}{|c|c|c|c|c|c|c|}
\hline First author, year [Ref.] & Sample & $\begin{array}{l}\text { NIBS } \\
\text { technique }\end{array}$ & Target site & $\begin{array}{l}\text { Stimulation } \\
\text { parameters and } \\
\text { design }\end{array}$ & $\begin{array}{l}\text { MRI scanner, } \\
\text { rs-fMRI } \\
\text { acquisition, } \\
\text { and analysis }\end{array}$ & Main results \\
\hline Rastogi, 2017 [63] & $\begin{array}{l}12 \text { young } \\
\text { adults }\end{array}$ & TBS & $\begin{array}{l}\text { Active: lateral } \\
\text { cerebellum }\end{array}$ & $\begin{array}{l}\text { One } 50-\mathrm{Hz} \text { session } \\
(80 \% \text { ATM }) \text {, cTBS } \\
\text { and sham carried out } \\
\text { at least } 2 \text { days apart }\end{array}$ & 3T, seed ROI & $\begin{array}{l}\text { Reduced FC between } \\
\text { stimulated site and frontal and } \\
\text { parietal regions }\end{array}$ \\
\hline
\end{tabular}

ACC, anterior cingulate cortex; atDCS, anodal transcranial direct current stimulation; ATM, active motor threshold; aI/fO, anterior insula/frontal operculum; B, bilateral; cTBS, continuous theta burst stimulation; ctDCS, cathodal transcranial direct current stimulation; DAN, dorsal attention network; DLPFC, dorsolateral prefrontal cortex: DMN, default mode network; FC, functional connectivity; FPN, frontoparietal network; GCA, granger causality analysis; HGal, Heschl's gyrus; ICA, independent component analysis; IFG, inferior frontal gyrus; iTBS, intermitting theta burst stimulation; IPL, inferior parietal lobe; L, left; M1, primary motor cortex; MD, medial dorsal; QPS, quadripulse stimulation; R, right; S1, primary somatosensory; SMA, supplementary motor area; TBS, theta burst stimulation; TMS, transcranial magnetic stimulation; tDCS, transcranial direct current stimulation; VPL, ventroposterolateral

Fig. 2. Common targets of NIBS reported in the literature (yellow spheres on $3 \mathrm{D}$ brain) are major nodes of large-scale functional networks. Each target can be used as a seed to derive functionally related (i.e., synchronous) regions of the brain. Stimulation of specific brain regions results in both local and distal functional connectivity modulation. Orange-yellow colors on axial slices represent the intrinsic functional connectivity degree ( $z$ score) of the major large-scale networks, extracted through independent component analysis from a sample of 20 healthy subjects.

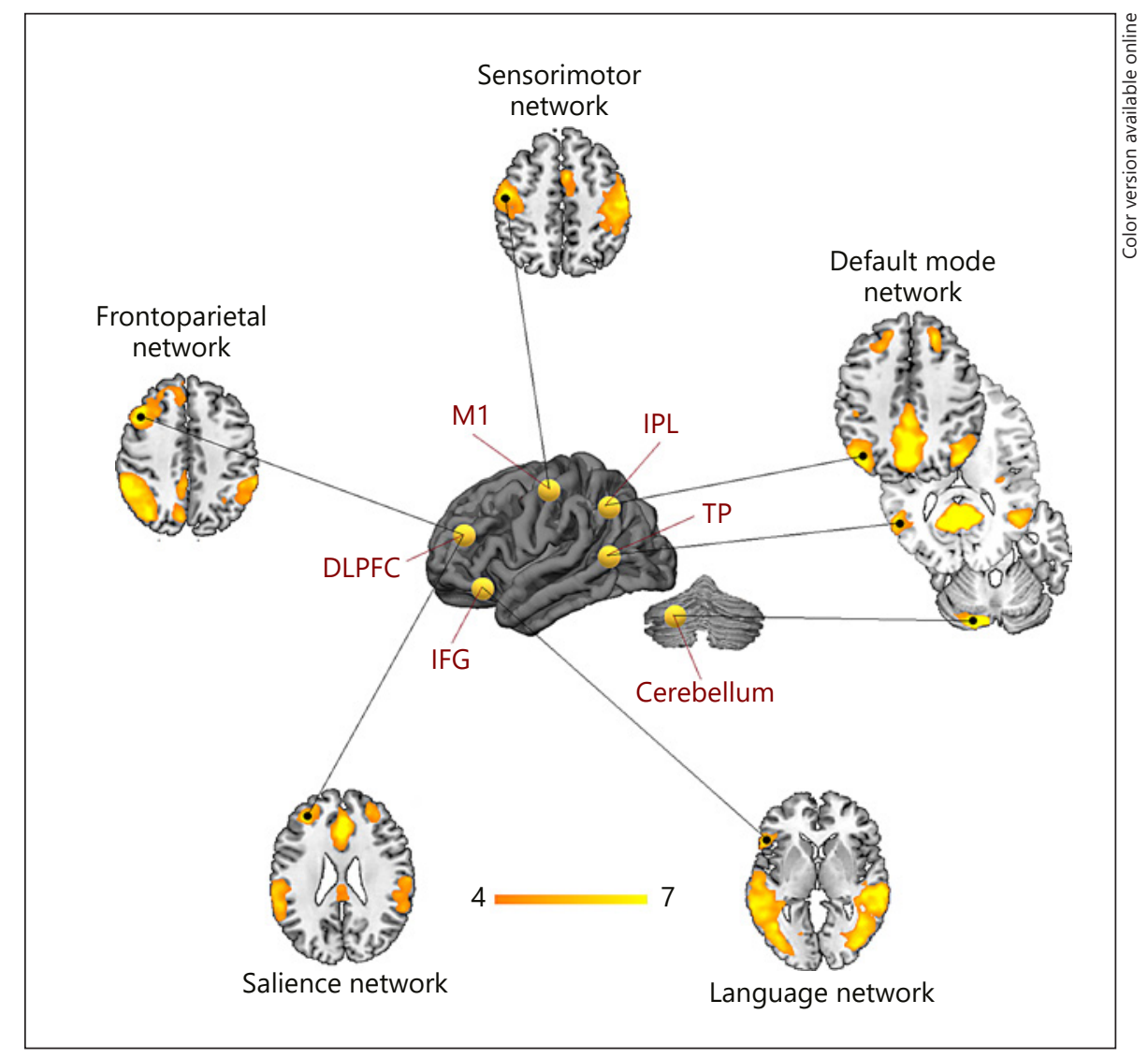

creased connectivity after atDCS. Increased functional connectivity (FC) was found both in regions proximal to the electrode $[30,34,38]$ and in distal regions belonging to the sensorimotor network $[31,36,39]$. Similarly, studies using graph theory, an approach taking into account network topology and synchronization between brain hubs [64], suggested a network-specific enhancement of connectivity following atDCS $[32,33,35,37]$. Taken together, these results suggest that atDCS targeting the motor cortex induce increased connectivity, exerting both local and distal effects within the sensorimotor network. However, in elderly atDCS seems to decrease FC of motor 
Fig. 3. Non-overlapping hubs for the major cognitive networks (language, frontoparietal, salience, and default mode networks). Maps were extracted through independent component analysis from a sample of 20 healthy subjects and overlaid into the MNI template. Circles highlight the spatial localization of non-convergent dorsal frontal and parietal hubs of each functional network.

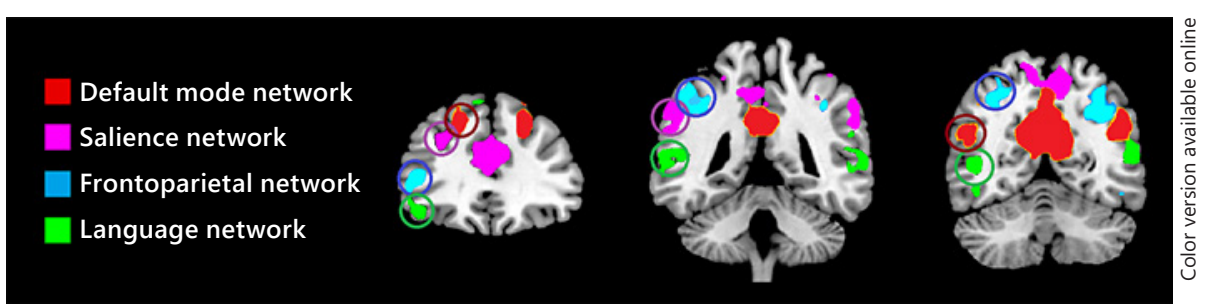

network suggesting a differential effect of atDCS due to age $[29,30]$, although the behavioral significance of these changes is not yet clear. The relationship between ctDCS and functional changes is also unclear, since variables effects have been reported to date (i.e., no change, increased, decreased FC) [28-30, 34].

Only one study has used TMS to investigate the relationship between polarity (high/low frequency) and FC changes in the motor network [40]. The study targeted the left M1 and reported reduced FC following excitatory TMS, while inhibitory TMS increased FC. This pattern differs from that reported for tDCS and suggests that the mechanism of action of the two methodologies might not be directly comparable.

Two studies have used TBS to test the effect of motor cortex inhibition. Inhibitory cTBS over the somatosensory cortex $(\mathrm{S} 1)$ reduced FC between the stimulated region and functionally connected motor network regions [42]. Similarly, cTBS over the bilateral auditory cortex reduced FC within the auditory network [41]. These studies suggest that cTBS may be more effective than ctDCS in inhibiting FC.

\section{Frontal and Parietal Cortex}

Studies targeting the dorsolateral prefrontal cortex (DLPFC), a key hub for executive functions, working memory and reasoning, consistently reported increased FC within the FPN after atDCS $[43,47,48]$. Studies targeting the temporo-parietal cortex, a key region of the DMN, reported relatively consistent changes within this network. Increased FC within the DMN was observed after 3 atDCS sessions targeting the right temporo-parietal cortex, and these changes were associated with better memory recall performance [55]. Similarly, Clemens et al. [57] reported increased FC within the anterior DMN after a single atDCS targeting the right angular gyrus, although divergent effects were reported for DMN posterior hubs $[56,57]$. These preliminary results suggest that atDCS over DLPFC and parietal cortex may be effective in modulating specific neural networks relying over these cortical hubs, the FPN and the DMN, respectively. Nevertheless, connectivity changes were also observed in other neural networks: frontal stimulation affected FC within the DMN $[43,47]$, the language network [44], and subcortical nuclei [36, 46]. Moreover, frontal stimulation resulted in interactions between FPN and DMN FC [47]. Similarly, parietal stimulation effects were not limited to the DMN but also involved the FPN and SN [57, 58].

The reason for these internetwork changes following tDCS remains to be elucidated. Between-networks effects may be related to accidental (co)stimulation of directly adjacent brain regions, which in turn may cause multiple network effects and even unexpected negative effects on cognitive outcomes [59]. To resolve this issue, rs-fMRI could be used to identify non-overlapping hubs from specific networks. Indeed, procedures of signal decomposition such as independent component analysis (ICA) enable to extract distinct (spatially non-overlapping) nodes for each network (Fig. 3). However, some degree of overlap between networks might be unavoidable. Macroscopic anatomical brain connectivity studies suggest a socalled "rich club" organization of the brain, whereby highly interconnected nodes show a strong tendency to connect with other highly connected nodes, thus resulting in numerous between-network connections [65]. While the sensorimotor network shows a relatively small proportion of rich club nodes (6-8\%), the DMN, SN, and FPN show considerably more rich club nodes (up to $23 \%$ ) [66]. Thus, although different DLPFC and posterior parietal subregions are exclusively part of a network, they may be highly interconnected, and this observation may, in part, explain the different neuromodulatory effects reported in the studies above. Conversely, the lower proportion of rich club within the sensorimotor network may explain the higher consistency between studies targeting motor cortex with atDCS electrodes and the relatively selective effect on this network. 
To date, only one study assessed local and distal connectivity effects following frontal stimulation in elderly [45]. After atDCS over the left IFG, participants significantly improved performance up to the level of younger controls, along with a "normalization" of network connectivity [45]. This finding provides the first evidence that NIBS may be suited to modulate brain networks connectivity in elderly populations.

Studies using TMS reported more variable findings. Three studies used TMS [49-51] and 3 TBS [52-54] to stimulate the DLPFC. Two studies showed coherent findings, i.e. increased FC within the frontal hub of the FPN after excitatory TMS [50], and reduced FPN after inhibitory TBS [54], while the others did not report differences in FPN connectivity after TMS/TBS $[49,51]$, or reported an inverted direction of effects (i.e., increased FC after inhibitory or decreased FC after excitatory TBS) $[52,53]$. Similarly, Eldaief et al. [60] using rs-fMRI at baseline to identify individual DMN parietal targets, reported opposite effects according to the frequency of TMS: low-frequency stimulation increased DMN FC, while high-frequency stimulation decreased it [60]. However, a subsequent study reported the opposite effect, i.e. inhibitory cTBS of the precuneus reduced DMN FC [61]. While the reason for the differences between TMS and TBS effects is unclear, it seems that the mechanism of action of the two techniques is different. Moreover, differences in methodology (i.e., stimulation parameters) may explain, at least in part, this discrepancy, as well as in the target (IPL vs. precuneus) and coil positioning and orientation, which are known to affect the neurophysiological response to TMS [67].

\section{Cerebellum}

Modulation of cognitive networks was also observed after the stimulation of cerebellar hubs, which are traditionally associated with motor functions. As in the study by Eldaief et al. [60], Halko et al. [62] used the baseline rs-fMRI of participants to localize the cerebellar node of the DMN. Stimulation through iTBS of the DMN-cerebellum node resulted in increased FC of cortical nodes of the DMN. Targeting the midline cerebellum, which is not part of the DMN, increased FC of the dorsal attention network [62]. Rastogi et al. [63] found reduced FC in frontal and parietal cognitive regions after cTBS of the crus I of the lateral cerebellum. These results confirm the modulatory effect of cerebellar stimulation on large-scale cognitive networks and the opposite effect of excitatory and inhibitory TBS on connectivity.

\section{Mechanisms of Network Modulation: Brain Neurometabolites}

The investigation of brain neurotransmitters in relation to NIBS effects can provide insight into the mechanisms of action of NIBS. Indeed, neuronal plasticity depends upon a complex balance between excitatory and inhibitory neurotransmitters: glutamate (Glu) is the main brain excitatory neurotransmitter, while the $\gamma$-aminobutyric acid (GABA) is the main inhibitory neurotransmitter [68]. Pharmacological studies indicate that excitatory changes induced by atDCS are Glu dependent but are also involving a reduction in GABA transmission [69], whereas the inhibitory effects induced by ctDCS seem to involve a reduction in Glu transmission [70]. Glutamatergic/GABAergic involvement is also observed in TMS-induced excitatory and inhibitory effects on the brain, which have been linked to long-term potentiation and long-term depression, respectively [71].

Neuroimaging can offer an alternative approach to pharmacological studies to study these mechanisms. The concentration of GABA and glutamatergic metabolites, Glu/glutamine (Glx), can be measured reliably in vivo with ${ }^{1} \mathrm{H}$ MRS [72], using "Spectral editing" techniques [73]. In recent years, these ${ }^{1} \mathrm{H}$ MRS techniques have been increasingly used in conjunction with NIBS and rs-fMRI in healthy adults (Table 2). The areas of interest (rs-fMRI) or targeting (NIBS) have been principally studied by using a single-voxel MRS technique and, to our best knowledge, the measurements of the GABA/Glx published are mainly relative (ratio), not absolute concentrations (Table 2).

The majority of these studies investigated neurometabolite changes in the motor cortex in young adults, reporting a consistent reduction of GABA after atDCS [31, 70, 75, 76], except for Tremblay et al. [77]. The above finding was generally coupled with increased FC over the motor network $[31,39]$, indicating that these connectivity changes may be driven by a decrease in the inhibitory neurotransmitter. Indeed, Stagg et al. [76] estimated a decrease of around $12 \%$ of GABA levels in the motor cortex following motor atDCS and an inverse correlation with motor network FC [39]. Conversely, the effects of ctDCS on brain metabolites levels are less clear, one study reporting no effect [75], and one decreased GABA and Glu levels [70]. Age may modulate the effects of NIBS on brain neurometabolites. One study to date has assessed this topic. Antonenko et al. [29] reported a reduction of GABA concentrations following atDCS together with a decreased FC in the sensorimotor cortex in elderly. This
Pini/Manenti/Cotelli/Pizzini/Frisoni/ Pievani 
Table 2. Non-invasive brain stimulation studies in healthy controls using ${ }^{1} \mathrm{H}$ MRS-derived metabolites as outcome measures

\begin{tabular}{|c|c|c|c|c|c|c|}
\hline $\begin{array}{l}\text { First author, } \\
\text { year [Ref.] }\end{array}$ & Sample & $\begin{array}{l}\text { NIBS } \\
\text { technique }\end{array}$ & Target site & $\begin{array}{l}\text { Stimulation param- } \\
\text { eters and design }\end{array}$ & $\begin{array}{l}\text { MRI scanner, MRS } \\
\text { sequence }\end{array}$ & Main results \\
\hline $\begin{array}{l}\text { Antonenko, } \\
2017 \text { [29] }\end{array}$ & 48 elderly & $\mathrm{tDCS}$ & $\begin{array}{l}\text { Active: L M1 } \\
\text { Reference: R } \\
\text { supraorbital }\end{array}$ & $\begin{array}{l}\text { One } 15 \text {-min session } \\
(1 \mathrm{~mA}) \text {, atDCS, } \\
\text { ctDCS, and sham } \\
\text { carried out } 1 \text { week } \\
\text { apart }\end{array}$ & $\begin{array}{l}\text { 3T, offline, MEGA- } \\
\text { PRESS, single voxel, } \\
\text { ratio to total creatine }\end{array}$ & $\begin{array}{l}\text { Reduced GABA in the stimulated } \\
\text { area after atDCS; no main effect } \\
\text { in glutamate, but post hoc } \\
\text { exploratory analysis revealed } \\
\text { reduced glutamate after ctDCS }\end{array}$ \\
\hline Clark, 2011 [74] & $\begin{array}{l}10 \text { young } \\
\text { adults }\end{array}$ & $\mathrm{tDCS}$ & $\begin{array}{l}\text { Active: R parietal } \\
\text { Reference: L upper } \\
\text { arm }\end{array}$ & $\begin{array}{l}\text { One } 30 \text {-min session } \\
(2 \mathrm{~mA}) \text {, atDCS }\end{array}$ & $\begin{array}{l}\text { 3T, offline, standard } \\
\text { PRESS, single, } \\
\text { concentration }\end{array}$ & $\begin{array}{l}\text { Increased Glx in the stimulated } \\
\text { area after atDCS }\end{array}$ \\
\hline Stagg, $2009[70]$ & $\begin{array}{l}11 \text { young } \\
\text { adults }\end{array}$ & $\mathrm{tDCS}$ & $\begin{array}{l}\text { Active: L M1 } \\
\text { Reference: R } \\
\text { supraorbital }\end{array}$ & $\begin{array}{l}\text { One } 10 \text {-min session } \\
(1 \mathrm{~mA}) \text {, atDCS, } \\
\text { ctDCS, and sham } \\
\text { carried out } 1 \text { week } \\
\text { apart }\end{array}$ & $\begin{array}{l}\text { 3T, offline MEGA- } \\
\text { PRESS, single, ratio } \\
\text { to creatine }\end{array}$ & $\begin{array}{l}\text { Reduced GABA in the stimulated } \\
\text { area after atDCS; reduced GABA } \\
\text { and Glx (driven by glutamate) in } \\
\text { the stimulated area after cTDCS }\end{array}$ \\
\hline Stagg, 2011 [76] & $\begin{array}{l}12 \text { young } \\
\text { adults }\end{array}$ & $\mathrm{tDCS}$ & $\begin{array}{l}\text { Active: L M1 } \\
\text { Reference: R } \\
\text { supraorbital }\end{array}$ & $\begin{array}{l}\text { Two } 10-\mathrm{min} \\
\text { sessions }(1 \mathrm{~mA}) \text {, } \\
\text { atDCS }\end{array}$ & $\begin{array}{l}\text { 3T, offline, MEGA- } \\
\text { PRESS, single, ratio } \\
\text { to NAA }\end{array}$ & $\begin{array}{l}\text { Reduced GABA in the stimulated } \\
\text { area after atDCS }\end{array}$ \\
\hline $\begin{array}{l}\text { Tremblay, } 2016 \\
\text { [77] }\end{array}$ & $\begin{array}{l}8 \text { young } \\
\text { adults }\end{array}$ & $\mathrm{tDCS}$ & $\begin{array}{l}\text { Active: L/R M1 } \\
\text { Reference: R/L M1 }\end{array}$ & $\begin{array}{l}\text { One } 20 \text {-min session } \\
(1 \mathrm{~mA}) \text {, atDCS } \mathrm{L} / \mathrm{R} \\
\text { and ctDCS R/L, and } \\
\text { sham carried out on } \\
3 \text { days }\end{array}$ & $\begin{array}{l}\text { 3T, offline, MEGA- } \\
\text { PRESS, single, } \\
\text { concentration }\end{array}$ & $\begin{array}{l}\text { No metabolites changes after } \\
\text { tDCS }\end{array}$ \\
\hline $\begin{array}{l}\text { Vidal-Piñeiro, } \\
2015 \text { [78] }\end{array}$ & $\begin{array}{l}36 \text { young } \\
\text { adults }\end{array}$ & TBS & Active: L IPL & $\begin{array}{l}\text { One } 50-\mathrm{Hz} \text { session } \\
(80 \% \text { AMT), iTBS, } \\
\text { or cTBS, or sham }\end{array}$ & $\begin{array}{l}\text { 3T, MEGA-PRESS, } \\
\text { single, ratio to total } \\
\text { creatine }\end{array}$ & $\begin{array}{l}\text { Increased GABA in distal area } \\
\text { (PCC-DMN) but not in the target } \\
\text { area after iTBS; no Glx change; } \\
\text { neurometabolites modulation in } \\
\text { PCC related to baseline } \\
\text { connectivity between PCC and } \\
\text { target site }\end{array}$ \\
\hline
\end{tabular}

atDCS, anodal transcranial direct current stimulation; ctDCS, anodal transcranial direct current stimulation; cathodal transcranial direct current stimulation; DLPFC, dorsolateral prefrontal cortex; DMN, default mode network; ctDCS; Glx: combined glutamate and glutamine; iTBS, intermitting theta burst stimulation; IPL, inferior parietal lobe; mA, milliamps; M1, Primary motor cortex; PCC, posterior cingulate cortex; PRESS, point-resolved spectroscopy; STEAM, Stimulated Echo Acquisition Mode; tDCS, transcranial direct current stimulation; TBS, theta burst stimulation.

pattern is different from that observed in young adults $[30,31,39]$. Stratification of the elderly sample into younger ( $<63$ age) and older ( $>63$ age) revealed a differential effect of atDCS-induced GABA modulation and network coupling: in younger, lower GABA correlated with higher sensorimotor strength (i.e., the same pattern observed in young adults), while in older the correlation was reversed [29]. Therefore, functional network reorga- 
Table 3. Non-invasive brain stimulation studies carried out in patients with cognitive decline and dementia

\begin{tabular}{|c|c|c|c|c|c|c|c|}
\hline $\begin{array}{l}\text { First author, year } \\
\text { [Ref.] }\end{array}$ & Sample & $\begin{array}{l}\text { NIBS } \\
\text { technique }\end{array}$ & Target site & $\begin{array}{l}\text { Stimulation parameters } \\
\text { and design }\end{array}$ & $\begin{array}{l}\text { Sessions and } \\
\text { training }\end{array}$ & MRI & Main results \\
\hline \multicolumn{8}{|c|}{ Alzheimer's disease } \\
\hline $\begin{array}{l}\text { Boggio, } \\
2009[82]\end{array}$ & $10 \mathrm{AD}$ & $\mathrm{tDCS}$ & $\begin{array}{l}\text { Active: } \mathrm{L} \text { frontal or } \\
\text { L temporal } \\
\text { Reference: } \mathrm{R} \\
\text { supraorbital }\end{array}$ & $\begin{array}{l}\text { One } 30 \text {-min session ( } 2 \\
\mathrm{~mA}) \text {, atDCS DLPFC, } \\
\text { atDCS temporal, and } \\
\text { sham carried out } 2 \\
\text { days apart }\end{array}$ & $\begin{array}{l}\text { Single; } \\
\text { no training }\end{array}$ & l & $\begin{array}{l}\text { Improved visual recognition } \\
\text { memory after both DLPFC } \\
\text { and temporal atDCS; no } \\
\text { improvement of attention }\end{array}$ \\
\hline $\begin{array}{l}\text { Boggio, } \\
2012 \text { [83] }\end{array}$ & $15 \mathrm{AD}$ & $\mathrm{tDCS}$ & $\begin{array}{l}\text { Active: B temporal } \\
\text { Reference: } \mathrm{R} \text { deltoid } \\
\text { muscle }\end{array}$ & $\begin{array}{l}\text { Five } 30 \text {-min sessions } \\
(2 \mathrm{~mA}) \text {, atDCS or } \\
\text { sham carried out } 1 \\
\text { month apart }\end{array}$ & $\begin{array}{l}\text { Multiple; } \\
\text { no training }\end{array}$ & l & $\begin{array}{l}\text { Improved visual recognition } \\
\text { memory after atDCS; no } \\
\text { global cognitive and visual } \\
\text { attention improvement }\end{array}$ \\
\hline $\begin{array}{l}\text { Ferrucci, } 2008 \\
{[85]}\end{array}$ & $10 \mathrm{AD}$ & $\mathrm{tDCS}$ & $\begin{array}{l}\text { Active: } B \text { temporal } \\
\text { Reference: } \mathrm{R} \text { deltoid } \\
\text { muscle }\end{array}$ & $\begin{array}{l}\text { One } 15-\min (1.5 \mathrm{~mA}) \text {, } \\
\text { atDCS, ctDCS, and } \\
\text { sham carried out } 1 \\
\text { week apart }\end{array}$ & $\begin{array}{l}\text { Single; } \\
\text { no training }\end{array}$ & I & $\begin{array}{l}\text { Improved verbal memory } \\
\text { task after atDCS, while } \\
\text { decreases after ctDCS }\end{array}$ \\
\hline $\begin{array}{l}\text { Khedr, } \\
2014 \text { [86] }\end{array}$ & $34 \mathrm{AD}$ & $\mathrm{tDCS}$ & $\begin{array}{l}\text { Active: } \mathrm{L} \text { frontal } \\
\text { Reference: } \mathrm{R} \\
\text { supraorbital }\end{array}$ & $\begin{array}{l}\text { Ten } 25 \text {-min sessions } \\
(2 \mathrm{~mA}) \text {, atDCS, ctDCS, } \\
\text { or sham }\end{array}$ & $\begin{array}{l}\text { Multiple; } \\
\text { no training }\end{array}$ & I & $\begin{array}{l}\text { Improved MMSE after both } \\
\text { atDCS and ctDCS, while } \\
\text { improved WAIS only after } \\
\text { ctDCS }\end{array}$ \\
\hline $\begin{array}{l}\text { Suemoto, } \\
2014 \text { [87] }\end{array}$ & $40 \mathrm{AD}$ & $\mathrm{tDCS}$ & $\begin{array}{l}\text { Active: L frontal } \\
\text { Reference: R orbit }\end{array}$ & $\begin{array}{l}\text { Six } 20 \text {-min sessions } \\
(2 \mathrm{~mA}) \text {, atDCS or } \\
\text { sham }\end{array}$ & $\begin{array}{l}\text { Multiple; } \\
\text { no training }\end{array}$ & I & $\begin{array}{l}\text { No cognitive and clinical } \\
\text { differences between atDCS } \\
\text { and sham }\end{array}$ \\
\hline $\begin{array}{l}\text { Cotelli, } \\
2011[90]\end{array}$ & $10 \mathrm{AD}$ & TMS & L frontal & $\begin{array}{l}\text { Twenty } 20-\mathrm{Hz} \text { sessions } \\
\text { (100\% ATM), } \\
\text { excitatory or excitatory } \\
\text { + sham }\end{array}$ & $\begin{array}{l}\text { Multiple; } \\
\text { no training }\end{array}$ & l & $\begin{array}{l}\text { Improved auditory sentence } \\
\text { comprehension after } \\
\text { excitatory TMS; no } \\
\text { improvement of naming } \\
\text { performance }\end{array}$ \\
\hline $\begin{array}{l}\text { Eliasova, } \\
2014[91]\end{array}$ & $10 \mathrm{AD}$ & TMS & $\begin{array}{l}\mathrm{R} \text { frontal or } \mathrm{R} \\
\text { temporal or vertex }\end{array}$ & $\begin{array}{l}\text { One } 10-\mathrm{Hz} \text { session } \\
\text { (90\% ATM), excitatory } \\
\text { IFG, excitatory STG, } \\
\text { and excitatory vertex } \\
\text { carried out } 1 \text { day apart }\end{array}$ & $\begin{array}{l}\text { Single; } \\
\text { no training }\end{array}$ & $\begin{array}{l}\text { sMRI for } \\
\text { target }\end{array}$ & $\begin{array}{l}\text { Improved attention and } \\
\text { psychomotor speed after } \\
\text { excitatory TMS of the R IFG }\end{array}$ \\
\hline Koch, 2018 [92] & $14 \mathrm{AD}$ & TMS & $\mathrm{L}$ parietal & $\begin{array}{l}\text { Ten } 20-\mathrm{Hz} \text { sessions } \\
\text { (100\% ATM), } \\
\text { excitatory sham carried } \\
\text { out } 2 \text { weeks apart }\end{array}$ & $\begin{array}{l}\text { Multiple; } \\
\text { no training }\end{array}$ & l & $\begin{array}{l}\text { Improved episodic memory } \\
\text { after excitatory TMS; no } \\
\text { change in other cognitive } \\
\text { domains; increased rs-EEG } \\
\text { activity in target site and } \\
\text { medial frontal DMN }\end{array}$ \\
\hline
\end{tabular}


Table 3 (continued)

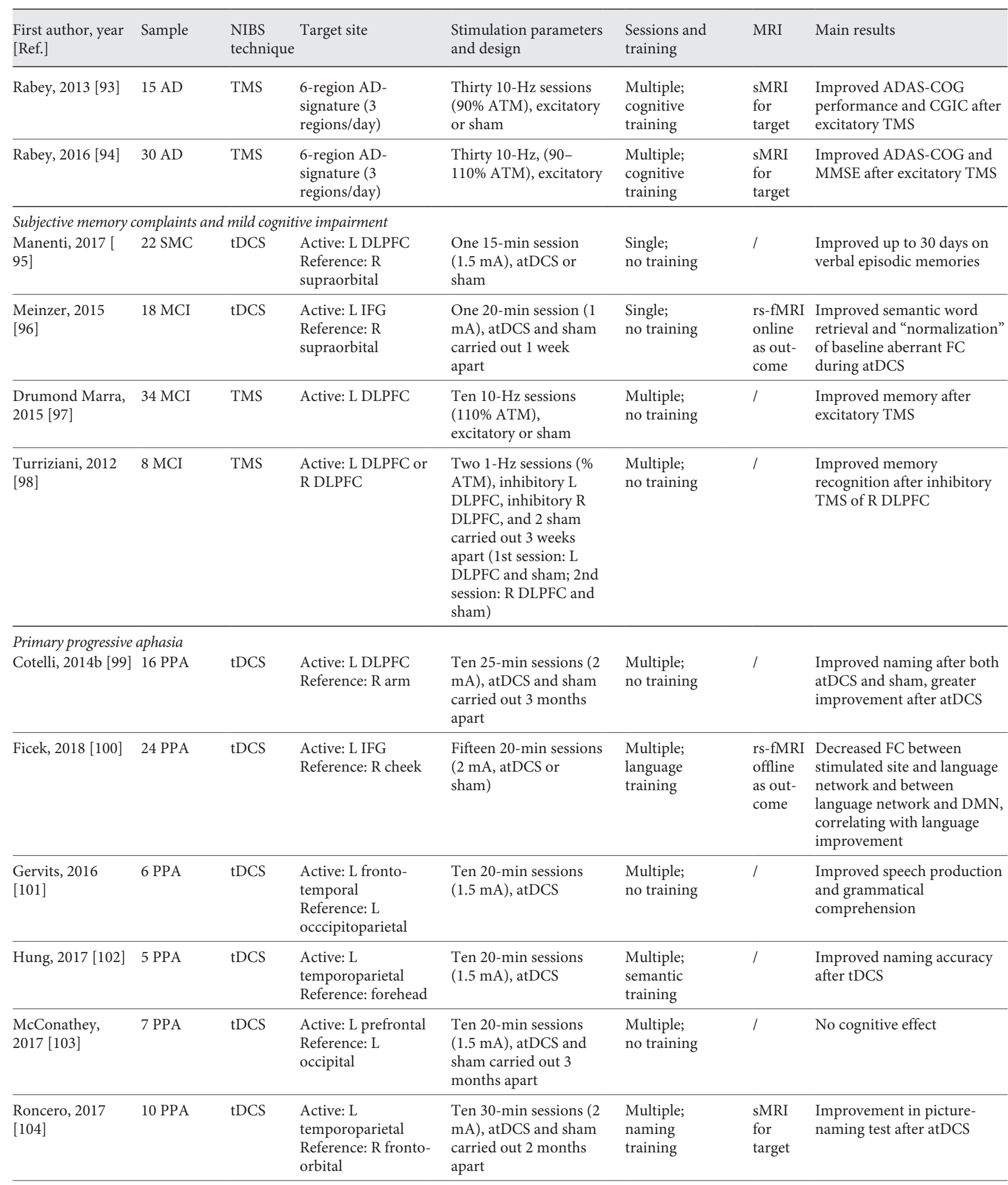


Table 3 (continued)

\begin{tabular}{|c|c|c|c|c|c|c|c|}
\hline $\begin{array}{l}\text { First author, year } \\
\text { [Ref.] }\end{array}$ & Sample & $\begin{array}{l}\text { NIBS } \\
\text { technique }\end{array}$ & Target site & $\begin{array}{l}\text { Stimulation parameters } \\
\text { and design }\end{array}$ & $\begin{array}{l}\text { Sessions and } \\
\text { training }\end{array}$ & MRI & Main results \\
\hline $\begin{array}{l}\text { Teichmann, } 2016 \\
\text { [105] }\end{array}$ & $12 \mathrm{PPA}$ & $\mathrm{tDCS}$ & $\begin{array}{l}\text { Active: anode over the } \\
\text { left or cathode over } \\
\text { the right temporal } \\
\text { Reference: R or L } \\
\text { supraorbital }\end{array}$ & $\begin{array}{l}\text { One } 20 \text {-min session } \\
(1.6 \mathrm{~mA}) \text {, atDCS } \mathrm{L} \text {, } \\
\text { ctDCS R, and sham } \\
\text { carried out } 1 \text { week } \\
\text { apart }\end{array}$ & $\begin{array}{l}\text { Single; } \\
\text { no training }\end{array}$ & $\begin{array}{l}\text { sMRI for } \\
\text { target }\end{array}$ & $\begin{array}{l}\text { Improved semantic accuracy } \\
\text { task after both atDCS and } \\
\text { ctDCS and improved } \\
\text { processing semantic speed } \\
\text { after ctDCS }\end{array}$ \\
\hline
\end{tabular}

Behavioral variant of frontotemporal dementia

Huey, 2007 [107] 9 bvFTD + 1 tDCS PPA

Reference: $\mathrm{R}$ supraorbital
Active: L prefrontal

One 40-min session (2 $\mathrm{mA})$, atDCS and sham carried out on separate sessions

\begin{tabular}{llll}
\hline Cotelli, & 16 bvFTD & tDCS & $\begin{array}{l}\text { Active: medial } \\
\text { frontal } \\
\text { 2018 }[108]\end{array}$ \\
& & Reference: inion
\end{tabular}
$(1.5 \mathrm{~mA})$, atDCS and sham carried out 2

\section{B DLPFC}

\section{Single; / No cognitive effects}

no training

$\begin{array}{ll}\begin{array}{l}\text { Single; } \\ \text { no training }\end{array} & / \\ \text { atDCS }\end{array}$
weeks apart

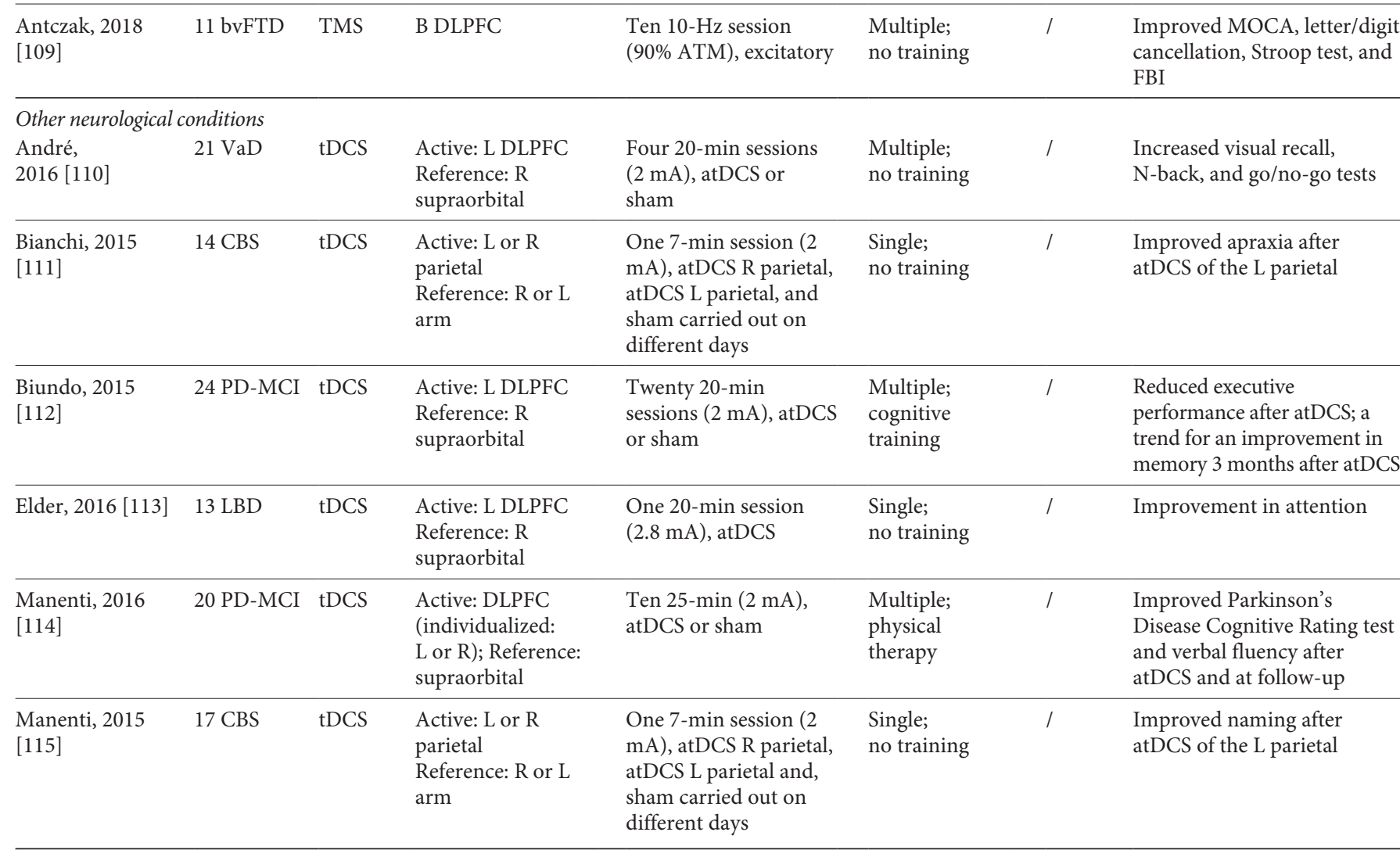

AD, Alzheimer's disease; ADAS-COG, Alzheimer's disease assessment scale-cognitive subscale; atDCS, anodal transcranial direct current stimulation; B, bilateral; ATM, active motor threshold; bvFTD, behavioral variant frontotemporal dementia; C, contralateral; CBS, corticobasal syndrome; CGIC, clinical global impression of change; ctDCS, cathodal transcranial direct current stimulation; DLPFC, dorsolateral prefrontal cortex; FBI, frontal behavioral inventory; GDS, geriatric depression scale; IADL, instrumental activities of daily living; IFG, inferior frontal gyrus; L, left; LBD, Lewy body dementia; MCI, mild cognitive impairment; MMSE, mini mental state examination; MOCA, Montreal cognitive assessment; Na, not available; PD, Parkinson's disease; PPA, primary progressive aphasia; R, right; SMC, subjective cognitive complaints; sMRI, structural MRI; STG, superior temporal gyrus; tDCS, transcranial direct current stimulation; TMS, transcranial magnetic stimulation; ToM, theory of mind; VaD, vascular dementia. 
nization may follow different trajectories in young and elderly, and the physiological significance of these changes (whether indicative of higher neuronal efficiency at different ages or impaired patterns in elderly) remains to be elucidated.

Two studies investigated the effect of atDCS over the parietal cortex, reporting increased Glx concentrations $[58,74]$, which suggests an increase in excitation. Notably, this is different from the effect reported in the motor cortex, which suggests a decrease in inhibition. However, these considerations are very preliminary, since the above studies did not measure GABA concentrations [58, 74]. The only study specifically investigating parietal after-effects of excitatory stimulation over both GABA and Glx used TBS and was aimed at DMN stimulation through the left IPL [78]. Inhibitory TBS induced distal GABA increases in the posteromedial DMN areas, with no local change in GABA or Glu [78]. Moreover, increments in distal GABA concentration were significantly related to baseline FC between the stimulated site and the posteromedial cortex, while nonsignificant Glx modulation after iTBS was inversely related to FC, suggesting that baseline connectivity patterns predict neurotransmitter modulation in distal areas.

Only one study to date has investigated the effect of frontal (DLPFC) cortex stimulation on brain metabolites. Iwabuchi et al. [53] reported a significant reduction in the GABA/Glx ratio following iTBS (suggesting reduced inhibition and/or increased excitation), although neither GABA nor Glx concentrations alone showed significant changes.

This preliminary evidence supports the idea that NIBS effects on functional networks may stem from modulation of GABAergic and glutamatergic pathways, in line with neuroimaging studies showing an association between metabolite levels and neural network connectivity $[79,80]$. However, future studies in larger samples are needed to disentangle the variability of NIBS-induced effects and the impact on neural networks of neurometabolite modulation.

\section{NIBS and Dementia}

NIBS is increasingly used to improve cognitive/behavioral deficits in neurodegenerative dementias or as a possible cognitive enhancer in preclinical stages (Table 3). A better understanding of the clinical effects of NIBS may be gained focusing on the complex interactions between the stimulation target and the associated brain networks. In this section, we will review previous NIBS studies carried out in dementia focusing on this specific aspect.

\section{Alzheimer's Disease}

For studies with AD patients, roughly half of studies employed tDCS as the stimulation tool [81-87], the other using TMS [88-94]. Moreover, the majority of the studies have focused on memory, the core clinical symptom. Ten studies were designed as multiple session paradigm [81, $83,84,86-88,90,92-94]$, and a cognitive training was combined with the stimulation protocol in 3 of the brain stimulation studies on AD [84, 93, 94].

Memory improvement was reported in 3 out of 5 studies targeting the temporal region [81-83, 85, 91]. According to the study by Antonenko et al. [55] in healthy older subjects, atDCS targeting the temporo-parietal cortex resulted in better memory, and this improvement was associated with increased DMN connectivity. Considering the role of DMN in supporting memory [15], it is conceivable that memory improvement following atDCS may be mediated by restoration of FC within the DMN. While the above studies did not investigate NIBS-related DMN changes, a recent investigation using TMS and EEG provide some preliminary support to this view. In a sample of $14 \mathrm{AD}$ patients, Koch et al. [92] reported improved episodic memory and increased EEG connectivity within the DMN after excitatory TMS over the precuneus. This region, part of the medial parietal component of the $\mathrm{DMN}$, displays aberrant connectivity in $\mathrm{AD}$ [19]. If confirmed with MRI approaches, this observation may indicate that memory improvement in $\mathrm{AD}$ following parietal excitatory stimulation may be mediated by DMN modulation.

Other studies in AD have targeted the frontal cortex, specifically the DLPFC, providing contrasting results in terms of memory benefits $[82,84,87]$. While one study reported a significant modulatory effect of atDCS on visual recognition memory [82], the other two did not report a stimulation benefit on memory tests $[84,87]$. The type of treatment protocol used could be responsible of the different results reported, since one of those investigations tested whether combining NIBS with cognitive training leads to a pronounced enhancement of training effects [84]. On the other hand, DLPFC modulation seems effective in improving global cognition, language, and attention abilities in $\mathrm{AD}$ patients $[86,88,89,91]$. Accordingly, the beneficial effects on non-memory abilities of NIBS over the frontal cortex may be related to modulation of other (non-DMN) networks. 


\section{Subjective Memory Complaints and Mild Cognitive Impairment}

Manenti et al. [95] investigated the effect of atDCS on the DLPFC in individuals with subjective memory complaints, a condition at greater risk of AD [116]. Their findings showed that a single session over the DLPFC was sufficient to strengthen episodic memory up to 1 month, relative to sham stimulation [95]. Similarly, DLPFC modulation showed beneficial memory effects in mild cognitive impairment (MCI) patients [97, 98], although these positive effects were obtained using different stimulation protocols (i.e., 10 excitatory sessions vs. 1 inhibitory session). In a sham-controlled study, Meinzer et al. [96] demonstrated that atDCS improved language performance in MCI patients after IFG stimulation. Connectivity analysis revealed a restoration of abnormal network configuration in the active group compared to sham condition in areas functionally connected to the stimulated IFG [96] and involved in language abilities [117].

\section{Primary Progressive Aphasia}

NIBS interventions in PPA are aimed at restoring language deficits. To date, all NIBS studies were carried out using tDCS and generally reported language enhancement. While there is some variability among studies in the target region, the majority stimulated areas involved in language, such as the left perisylvian cortex $[102,104]$, left anterior temporal pole [105], left frontotemporal cortex [101], but also areas within the dorsal frontal cortex (left DLPFC and IFG) [99, 100, 106]. Interestingly, 7 of the 8 studies were designed as multiple-session paradigm $[99-104,106]$ and 4 of them combined a cognitive training with the stimulation protocol $[100,102,104,106]$.

The above studies did not collect surrogate measures of neuronal changes; thus, the mechanism underlying cognitive improvement cannot be elucidated; however, one recent study suggests that language improvement might be driven by modulation of the language network but also by between-network changes. In a relatively large cohort of PPA patients $(n=24)$ treated in a crossover design, Ficek et al. [100] found that atDCS over the left IFG combined with speech and language interventions was more beneficial than sham combined with speech and language interventions. Significant tDCS effects in FC were observed between the stimulated area and the language network hubs and between the language network and the DMN (i.e., reduced connectivity), and these changes correlated with improvement in language scores. These results are in line with similar decreases in connectivity observed after tDCS over the left IFG in aging and
MCI [45, 96], suggesting that language improvement might be mediated by uncoupling between networks.

\section{Behavioral Variant Frontotemporal Dementia}

To our knowledge, only 3 studies have investigated NIBS effect in bvFTD patients. Only one study used multiple sessions [109] and none combined a cognitive training with the stimulation protocol. In all cases, the target region was the frontal cortex (dorsal or medial prefrontal cortex). Huey et al. [107] did not report any improvement in a sample of 10 FTD ( 9 bvFTD and 1 PPA) patients following a single atDCS stimulation targeting the prefrontal cortex. However, the choice of the outcome (language rather than behavioral domain) might have not been sensible to detect NIBS changes in this population. Recently, 2 studies performed NIBS targeting the frontal cortex with tDCS [108] or TMS [109], showing improvement in social cognitive ability [108], global cognition, and behavioral symptoms [109]. However, none of these studies collected surrogate imaging markers and one can only speculate on the possible networks modulating these effects. Based on previous studies, enhancement of behavioral symptoms might be effective through SN modulation, while modulation of social cognition activity might require targeting the $\mathrm{SN}, \mathrm{DMN}$, and attention network.

Overall, these results are promising for the treatment of bvFTD, for which therapeutic options are lacking. However, future studies should directly investigate NIBSmodulatory effects on neural networks involved in FTD, such as the $\mathrm{SN}, \mathrm{DMN}$, and attention network.

\section{Other Neurological Conditions}

In the last years, NIBS studies have been conducted in neurological disorders such as vascular dementia (VaD), Lewy body dementia (LBD), PD and CBS.

In $\mathrm{VaD}$, extensive white matter lesions result in global cognitive slowing and frontal-executive dysfunctions [118]. André et al. [110] investigated the effect of four daily sessions of $2 \mathrm{~mA}$ anodal or sham at-home tDCS applied to the left DLPFC in 21 patients with mild VaD. The left DLPFC was chosen as the target given its relevance in the modulation of executive functions. As expected, atDCS was able to improve the performance on executive tests [110].

Executive dysfunction is also present in PD and in LBD from the early stages [119]. Two independent studies in PD with MCI modulating the DLPFC however showed contrasting results. Biundo et al. [112] did not report improvements in executive functions after atDCS combined with cognitive training. In contrast, Manenti et 
al. [114], testing 2 weeks of atDCS combined with physical training, observed significant improvement of the Parkinson's disease cognitive rating test and verbal fluency, with a significant effect also at follow-up [114]. One study in DLB reported improvement in attention functions after 1 session of tDCS in a sample of LBD [113].

These studies generally used the DLPFC as a target, due to the key role of this region in executive functions. Studies in healthy subjects suggest that the executive function benefits may be mediated by FPN modulation $[43,47,48]$. Therefore, DLPFC modulation through NIBS may be an effective strategy to modulate executive functions in all those neurological disorders suffering from executive dysfunction. While the above studies are promising, they are still preliminary, and replication in larger, placebo-controlled trials is needed. Moreover, the effect of alternative approaches has yet to be investigated. For example, PD is primarily a disease of the cerebello-thalamo-cortical network, and assessing these networks might help to identify novel targets to inform on the mechanisms of cognitive/motor improvement.

CBS is a progressive neurodegenerative disease characterized by marked movement deficits and cognitive dysfunction and is associated with atrophy of the motor (parietal) cortex [120]. To date, 2 studies have investigated the effects of atDCS targeting the left parietal cortex and reporting improved naming abilities and apraxia after stimulation $[111,115]$. These studies used the parietal cortex as a target, due to the key role of this region in frontoparietal network. While the above studies could pave the way to useful rehabilitation techniques in these patients, they are still preliminary, and replication in larger, placebo-controlled trials is needed. Moreover, the effect of alternative approaches such as the stimulation of sensorimotor network, which is generally impaired in CBS pathology, has yet to be investigated. Further investigations might help to identify novel targets to inform on the mechanisms of cognitive/motor improvement in CBS.

\section{Conclusions}

NIBS has the potential to modulate the functional organization of brain large-scale networks. The reviewed literature indicates that NIBS affects both local and distal regions. Studies focusing on motor cortex consistently showed modulation of the sensorimotor network, while the effect of parietal and frontal cortex stimulation was more heterogeneous, although preliminary evidence seems to point to an involvement of the DMN and FPN, respectively. Importantly, the stimulation of regions belonging to cognitive networks (e.g., frontal and parietal cortex) demonstrated off-target effects (e.g., betweennetwork changes), which were not observed for the sensorimotor network. Overall, findings suggest that modulation of neural networks following NIBS does not rely on a simple 1:1 relationship between brain target and a given network, but several factors may interact to influence the results. For instance, age is one of the most important variables that may influence functional modulation.

Microscale changes observed with the ${ }^{1} \mathrm{H}$ MRS technique may help to better understand the mechanisms underlying functional modulation, such as the influence of GABA versus glutamate on the observed effects, although the limited number of studies available thus far does not allow to reach univocal conclusions. Again, studies investigating the effect on brain metabolites reported relatively consistent findings when modulating the motor cortex, while findings were more complex when studies modulated cognitive networks.

In conclusion, in neurodegenerative disorders, the association between cognitive/clinical deficits and network dysfunction supports a "network" approach targeting neural networks linked with the clinical phenotype. The combination of NIBS with neuroimaging is a promising approach to better understand the mechanisms of neuromodulation and to design targeted interventions for neurocognitive diseases.

\section{Statement of Ethics}

All data included were collected according to the Helsinki Declaration and approved by the local ethics committee of the IRCCS Istituto Centro San Giovanni di Dio Fatebenefratelli, Brescia, Italy. All participants signed written informed participation consent.

\section{Disclosure Statement}

The authors declare no conflicts of interest.

\section{Funding Sources}

This work was supported by the Italian Ministry of Health (Giovani Ricercatori grant GR2011-02349787 and Ricerca Corrente). 


\section{References}

1 Winblad B, Amouyel P, Andrieu S, Ballard C, Brayne $\mathrm{C}$, Brodaty $\mathrm{H}$, et al. Defeating Alzheimer's disease and other dementias: a priority for European science and society. Lancet Neurol. 2016 Apr;15(5):455-532.

2 Woods AJ, Antal A, Bikson M, Boggio PS, Brunoni AR, Celnik $\mathrm{P}$, et al. A technical guide to tDCS, and related non-invasive brain stimulation tools. Clin Neurophysiol. 2016 Feb; 127(2):1031-48.

3 Hoogendam JM, Ramakers GM, Di Lazzaro V. Physiology of repetitive transcranial magnetic stimulation of the human brain. Brain Stimul. 2010 Apr;3(2):95-118.

4 Bikson M, Name A, Rahman A. Origins of specificity during tDCS: anatomical, activityselective, and input-bias mechanisms. Front Hum Neurosci. 2013 Oct;7:688.

5 Hallett M. Transcranial magnetic stimulation: a primer. Neuron. 2007 Jul;55(2):18799.

6 Sandrini M, Umiltà C, Rusconi E. The use of transcranial magnetic stimulation in cognitive neuroscience: a new synthesis of methodological issues. Neurosci Biobehav Rev. 2011 Jan;35(3):516-36.

7 Nitsche MA, Paulus W. Excitability changes induced in the human motor cortex by weak transcranial direct current stimulation. J Physiol. 2000 Sep;527(Pt 3):633-9.

8 Conte A, Rocchi L, Nardella A, Dispenza S, Scontrini A, Khan N, et al. Theta-burst stimulation-induced plasticity over primary somatosensory cortex changes somatosensory temporal discrimination in healthy humans. PLoS One. 2012;7(3):e32979.

9 Huang YZ, Edwards MJ, Rounis E, Bhatia KP, Rothwell JC. Theta burst stimulation of the human motor cortex. Neuron. 2005 Jan; 45(2):201-6.

10 Lefaucheur JP, Antal A, Ayache SS, Benninger DH, Brunelin J, Cogiamanian F, et al. Evidence-based guidelines on the therapeutic use of transcranial direct current stimulation (tDCS). Clin Neurophysiol. 2017 Jan;128(1) 56-92.

11 Lefaucheur JP, André-Obadia N, Antal A, Ayache SS, Baeken C, Benninger DH, et al. Evidence-based guidelines on the therapeutic use of repetitive transcranial magnetic stimulation (rTMS). Clin Neurophysiol. 2014 Nov; 125(11):2150-206.

12 Bestmann S, de Berker AO, Bonaiuto J. Understanding the behavioural consequences of noninvasive brain stimulation. Trends Cogn Sci. 2015 Jan;19(1):13-20.

13 Bergmann TO, Karabanov A, Hartwigsen G, Thielscher A, Siebner HR. Combining noninvasive transcranial brain stimulation with neuroimaging and electrophysiology: current approaches and future perspectives. Neuroimage. 2016 Oct;140:4-19.
14 Pievani M, Filippini N, van den Heuvel MP, Cappa SF, Frisoni GB. Brain connectivity in neurodegenerative diseases-from phenotype to proteinopathy. Nat Rev Neurol. 2014 Nov;10(11):620-33.

15 Ranganath C, Ritchey M. Two cortical systems for memory-guided behaviour. Nat Rev Neurosci. 2012 Oct;13(10):713-26.

16 Laird AR, Fox PM, Eickhoff SB, Turner JA, Ray KL, McKay DR, et al. Behavioral interpretations of intrinsic connectivity networks. J Cogn Neurosci. 2011 Dec;23(12):4022-37.

17 Menon V. Large-scale brain networks and psychopathology: a unifying triple network model. Trends Cogn Sci. 2011 Oct;15(10): 483-506.

18 Warren JD, Rohrer JD, Schott JM, Fox NC Hardy J, Rossor MN. Molecular nexopathies: a new paradigm of neurodegenerative disease. Trends Neurosci. 2013 Oct;36(10):561-9.

19 Gour N, Felician O, Didic M, Koric L, Gueriot $\mathrm{C}$, Chanoine V, et al. Functional connectivity changes differ in early and late-onset Alzheimer's disease. Hum Brain Mapp. 2014 Jul; 35(7):2978-94.

20 Lehmann M, Madison C, Ghosh PM, Miller ZA, Greicius MD, Kramer JH, et al. Loss of functional connectivity is greater outside the default mode network in nonfamilial earlyonset Alzheimer's disease variants. Neurobiol Aging. 2015 Oct;36(10):2678-86.

21 Gorno-Tempini ML, Hillis AE, Weintraub S, Kertesz A, Mendez M, Cappa SF, et al. Classification of primary progressive aphasia and its variants. Neurology. 2011 Mar;76(11): 1006-14.

22 Mesulam MM, Rogalski EJ, Wieneke C, Hurley RS, Geula C, Bigio EH, et al. Primary progressive aphasia and the evolving neurology of the language network. Nat Rev Neurol. 2014 Oct;10(10):554-69.

23 Rascovsky K, Hodges JR, Knopman D, Mendez MF, Kramer JH, Neuhaus J, et al. Sensitivity of revised diagnostic criteria for the behavioural variant of frontotemporal dementia. Brain. 2011 Sep;134(Pt 9):2456-77.

24 Zhou J, Greicius MD, Gennatas ED, Growdon ME, Jang JY, Rabinovici GD, et al. Divergent network connectivity changes in behavioural variant frontotemporal dementia and Alzheimer's disease. Brain. 2010 May;133(Pt 5): 1352-67.

25 Crutch SJ, Schott JM, Rabinovici GD, Murray M, Snowden JS, van der Flier WM, et al.; Alzheimer's Association ISTAART Atypical Alzheimer's Disease and Associated Syndromes Professional Interest Area. Consensus classification of posterior cortical atrophy. Alzheimers Dement. 2017 Aug;13(8):870-84.

26 Bharti K, Bologna M, Upadhyay N, Piattella MC, Suppa A, Petsas N, et al. Abnormal Resting-State Functional Connectivity in Progressive Supranuclear Palsy and Corticobasal Syndrome. Front Neurol. 2017 Jun;8:248.
27 Pievani M, Pini L, Cappa SF, Frisoni GB. Brain networks stimulation in dementia: insights from functional imaging. Curr Opin Neurol. 2016 Dec;29(6):756-62.

28 Amadi U, Ilie A, Johansen-Berg H, Stagg CJ. Polarity-specific effects of motor transcranial direct current stimulation on fMRI resting state networks. Neuroimage. 2014 Mar; 88: 155-61.

29 Antonenko D, Schubert F, Bohm F, Ittermann B, Aydin S, Hayek D, et al. tDCS-Induced Modulation of GABA Levels and Resting-State Functional Connectivity in Older Adults. J Neurosci. 2017 Apr;37(15):4065-73.

30 Antonenko D, Nierhaus T, Meinzer M, Prehn $\mathrm{K}$, Thielscher A, Ittermann B, et al. Age-dependent effects of brain stimulation on network centrality. Neuroimage. 2018a Aug;176: 71-82.

31 Bachtiar V, Near J, Johansen-Berg H, Stagg CJ. Modulation of GABA and resting state functional connectivity by transcranial direct current stimulation. eLife. 2015 Sep;4:e08789.

32 Lindenberg R, Sieg MM, Meinzer M, Nachtigall L, Flöel A. Neural correlates of unihemispheric and bihemispheric motor cortex stimulation in healthy young adults. Neuroimage. 2016 Oct; $140: 141-9$.

33 Polanía R, Paulus W, Antal A, Nitsche MA Introducing graph theory to track for neuroplastic alterations in the resting human brain: a transcranial direct current stimulation study. Neuroimage. 2011 Feb;54(3):2287-96.

34 Polanía R, Paulus W, Nitsche MA. Modulating cortico-striatal and thalamo-cortical functional connectivity with transcranial direct current stimulation. Hum Brain Mapp. 2012a Oct;33(10):2499-508.

35 Polanía R, Paulus W, Nitsche MA. Reorganizing the intrinsic functional architecture of the human primary motor cortex during rest with non-invasive cortical stimulation. PLoS One. 2012b;7(1):e30971.

36 Sankarasubramanian V, Cunningham DA, Potter-Baker KA, Beall EB, Roelle SM, Varnerin NM, et al. Transcranial Direct Current Stimulation Targeting Primary Motor Versus Dorsolateral Prefrontal Cortices: Proof-ofConcept Study Investigating Functional Connectivity of Thalamocortical Networks Specific to Sensory-Affective Information Processing. Brain Connect. 2017 Apr;7(3): 182-96.

37 Sehm B, Schäfer A, Kipping J, Margulies D, Conde V, Taubert $\mathrm{M}$, et al. Dynamic modulation of intrinsic functional connectivity by transcranial direct current stimulation. J Neurophysiol. 2012 Dec;108(12):3253-63.

38 Sehm B, Kipping J, Schäfer A, Villringer A, Ragert P. A Comparison between Uni- and Bilateral tDCS Effects on Functional Connectivity of the Human Motor Cortex. Front Hum Neurosci. 2013 May;7:183. 
39 Stagg CJ, Bachtiar V, Amadi U, Gudberg CA, Ilie AS, Sampaio-Baptista C, et al. Local GABA concentration is related to networklevel resting functional connectivity. eLife. 2014 Mar;3:e01465.

40 Watanabe T, Hanajima R, Shirota Y, Ohminami S, Tsutsumi R, Terao Y, et al. Bidirectional effects on interhemispheric restingstate functional connectivity induced by excitatory and inhibitory repetitive transcranial magnetic stimulation. Hum Brain Mapp. 2014 May;35(5):1896-905.

41 Andoh J, Matsushita R, Zatorre RJ. Asymmetric Interhemispheric Transfer in the Auditory Network: Evidence from TMS, Resting-State fMRI, and Diffusion Imaging. J Neurosci. 2015 Oct;35(43):14602-11.

42 Valchev N, Ćurčić-Blake B, Renken RJ, Avenanti A, Keysers C, Gazzola V, et al. cTBS delivered to the left somatosensory cortex changes its functional connectivity during rest. Neuroimage. 2015 Jul;114:386-97.

43 Keeser D, Meindl T, Bor J, Palm U, Pogarell $\mathrm{O}$, Mulert C, et al. Prefrontal transcranial direct current stimulation changes connectivity of resting-state networks during fMRI. J Neurosci. 2011 Oct;31(43):15284-93.

44 Meinzer M, Antonenko D, Lindenberg R, Hetzer S, Ulm L, Avirame K, et al. Electrical brain stimulation improves cognitive performance by modulating functional connectivity and task-specific activation. J Neurosci. 2012 Feb;32(5):1859-66.

45 Meinzer $M$, Lindenberg $R$, Antonenko D, Flaisch T, Flöel A. Anodal transcranial direct current stimulation temporarily reverses ageassociated cognitive decline and functional brain activity changes. J Neurosci. $2013 \mathrm{Jul}$; 33(30):12470-8.

46 Park $\mathrm{CH}$, Chang WH, Park JY, Shin YI, Kim ST, Kim YH. Transcranial direct current stimulation increases resting state interhemispheric connectivity. Neurosci Lett. 2013 Feb; 539:7-10.

47 Peña-Gómez C, Sala-Lonch R, Junqué C, Clemente IC, Vidal D, Bargalló N, et al. Modulation of large-scale brain networks by transcranial direct current stimulation evidenced by resting-state functional MRI. Brain Stimul. 2012 Jul;5(3):252-63.

48 Wörsching J, Padberg F, Helbich K, Hasan A, Koch L, Goerigk S, et al. Test-retest reliability of prefrontal transcranial Direct Current Stimulation (tDCS) effects on functional MRI connectivity in healthy subjects. Neuroimage. 2017 Jul;155:187-201.

49 Bilek E, Schäfer A, Ochs E, Esslinger C, Zangl M, Plichta MM, et al. Application of high-frequency repetitive transcranial magnetic stimulation to the DLPFC alters human prefrontal-hippocampal functional interaction. J Neurosci. 2013 Apr;33(16):7050-6.
50 Tik M, Hoffmann A, Sladky R, Tomova L, Hummer A, Navarro de Lara L, et al. Towards understanding rTMS mechanism of action: stimulation of the DLPFC causes networkspecific increase in functional connectivity. Neuroimage. 2017 Nov;162:289-96.

51 van der Werf YD, Sanz-Arigita EJ, Menning $S$, van den Heuvel OA. Modulating spontaneous brain activity using repetitive transcranial magnetic stimulation. BMC Neurosci. 2010 Nov;11(1):145.

52 Gratton C, Lee TG, Nomura EM, D’Esposito $M$. The effect of theta-burst TMS on cognitive control networks measured with resting state fMRI. Front Syst Neurosci. 2013 Dec;7:124.

53 Iwabuchi SJ, Raschke F, Auer DP, Liddle PF, Lankappa ST, Palaniyappan L. Targeted transcranial theta-burst stimulation alters fronto-insular network and prefrontal GABA. Neuroimage. 2017 Feb;146:395-403.

54 Mastropasqua C, Bozzali M, Ponzo V, Giulietti G, Caltagirone C, Cercignani $M$, et al. Network based statistical analysis detects changes induced by continuous theta-burst stimulation on brain activity at rest. Front Psychiatry. 2014 Aug;5:97.

55 Antonenko D, Külzow N, Sousa A, Prehn K, Grittner U, Flöel A. Neuronal and behavioral effects of multi-day brain stimulation and memory training. Neurobiol Aging. 2018b Jan;61:245-54

56 Callan DE, Falcone B, Wada A, Parasuraman R. Simultaneous tDCS-fMRI Identifies Resting State Networks Correlated with Visual Search Enhancement. Front Hum Neurosci. 2016 Mar; 10:72.

57 Clemens B, Jung S, Mingoia G, Weyer D, Domahs F, Willmes K. Influence of anodal transcranial direct current stimulation (tDCS) over the right angular gyrus on brain activity during rest. PLoS One. 2014 Apr; 9(4):e95984.

58 Hunter MA, Coffman BA, Gasparovic C, Calhoun VD, Trumbo MC, Clark VP. Baseline effects of transcranial direct current stimulation on glutamatergic neurotransmission and large-scale network connectivity. Brain Res. 2015 Jan;1594:92-107.

59 Möller A, Nemmi F, Karlsson K, Klingberg T. Transcranial Electric Stimulation Can Impair Gains during Working Memory Training and Affects the Resting State Connectivity. Front Hum Neurosci. 2017 Jul;11:364.

60 Eldaief MC, Halko MA, Buckner RL, PascualLeone A. Transcranial magnetic stimulation modulates the brain's intrinsic activity in a frequency-dependent manner. Proc Natl Acad Sci USA. 2011 Dec;108(52):21229-34.

61 Mancini M, Mastropasqua C, Bonnì S, Ponzo V, Cercignani M, Conforto S, et al. Theta Burst Stimulation of the Precuneus Modulates Resting State Connectivity in the Left Temporal Pole. Brain Topogr. 2017 May; 30(3):312-9.
62 Halko MA, Farzan F, Eldaief MC, Schmahmann JD, Pascual-Leone A. Intermittent theta-burst stimulation of the lateral cerebellum increases functional connectivity of the default network. J Neurosci. 2014 Sep;34(36): 12049-56.

63 Rastogi A, Cash R, Dunlop K, Vesia M, Kucyi A, Ghahremani A, et al. Modulation of cognitive cerebello-cerebral functional connectivity by lateral cerebellar continuous theta burst stimulation. Neuroimage. 2017 Sep;158:4857.

64 Bullmore E, Sporns O. Complex brain networks: graph theoretical analysis of structural and functional systems. Nat Rev Neurosci. 2009 Mar; 10(3):186-98

65 van den Heuvel MP, Sporns O. Rich-club organization of the human connectome. J Neurosci. 2011 Nov;31(44):15775-86.

66 van den Heuvel MP, Sporns O. An anatomical substrate for integration among functional networks in human cortex. J Neurosci. 2013 Sep;33(36): 14489-500.

67 Laakso I, Hirata A, Ugawa Y. Effects of coil orientation on the electric field induced by TMS over the hand motor area. Phys Med Biol. 2014 Jan;59(1):203-18.

68 Nakanishi S, Nakajima Y, Masu M, Ueda Y, Nakahara K, Watanabe D, et al. Glutamate receptors: brain function and signal transduction. Brain Res Brain Res Rev. 1998 May;26(23):230-5.

69 Nitsche MA, Fricke K, Henschke U, Schlitterlau A, Liebetanz D, Lang N, et al. Pharmacological modulation of cortical excitability shifts induced by transcranial direct current stimulation in humans. J Physiol. 2003 Nov; 553(Pt 1):293-301.

70 Stagg CJ, Best JG, Stephenson MC, O'Shea J, Wylezinska M, Kincses ZT, et al. Polarity-sensitive modulation of cortical neurotransmitters by transcranial stimulation. J Neurosci. 2009 Apr;29(16):5202-6.

71 Demirtas-Tatlidede A, Vahabzadeh-Hagh AM, Pascual-Leone A. Can noninvasive brain stimulation enhance cognition in neuropsychiatric disorders? Neuropharmacology. 2013 Jan;64:566-78.

72 Mullins PG, McGonigle DJ, O'Gorman RL, Puts NA, Vidyasagar R, Evans CJ, et al.; Cardiff Symposium on MRS of GABA. Current practice in the use of MEGA-PRESS spectroscopy for the detection of GABA. Neuroimage. $2014 \mathrm{Feb} ; 86: 43-52$.

73 Zhu H, Barker PB. MR spectroscopy and spectroscopic imaging of the brain. Methods Mol Biol. 2011;711:203-26.

74 Clark VP, Coffman BA, Trumbo MC, Gasparovic $C$. Transcranial direct current stimulation (tDCS) produces localized and specific alterations in neurochemistry: a ${ }^{1} \mathrm{H}$ magnetic resonance spectroscopy study. Neurosci Lett. 2011 Aug;500(1):67-71. 
75 Kim S, Stephenson MC, Morris PG, Jackson SR. tDCS-induced alterations in GABA concentration within primary motor cortex predict motor learning and motor memory: a $7 \mathrm{~T}$ magnetic resonance spectroscopy study. Neuroimage. 2014 Oct;99:237-43.

76 Stagg CJ, Bachtiar V, Johansen-Berg H. The role of GABA in human motor learning. Curr Biol. 2011 Mar;21(6):480-4.

77 Tremblay S, Lafleur LP, Proulx S, Beaulé V, Latulipe-Loiselle A, Doyon J, et al. The effects of bi-hemispheric M1-M1 transcranial direct current stimulation on primary motor cortex neurophysiology and metabolite concentration. Restor Neurol Neurosci. 2016 May; 34(4):587-602.

78 Vidal-Piñeiro D, Martín-Trias P, Falcón C, Bargalló N, Clemente IC, Valls-Solé J, et al. Neurochemical Modulation in Posteromedial Default-mode Network Cortex Induced by Transcranial Magnetic Stimulation. Brain Stimul. 2015 Sep-Oct;8(5):937-44.

79 Northoff G, Walter M, Schulte RF, Beck J, Dydak U, Henning A, et al. GABA concentrations in the human anterior cingulate cortex predict negative BOLD responses in $\mathrm{AMRI}$. Nat Neurosci. 2007 Dec;10(12):1515-7.

80 Kapogiannis D, Reiter DA, Willette AA, Mattson MP. Posteromedial cortex glutamate and GABA predict intrinsic functional connectivity of the default mode network. Neuroimage. 2013 Jan;64:112-9.

81 Bystad M, Grønli O, Rasmussen ID, Gundersen $\mathrm{N}$, Nordvang L, Wang-Iversen $\mathrm{H}$, et al. Transcranial direct current stimulation as a memory enhancer in patients with Alzheimer's disease: a randomized, placebo-controlled trial. Alzheimers Res Ther. 2016 Mar; $8(1): 13$.

82 Boggio PS, Khoury LP, Martins DC, Martins OE, de Macedo EC, Fregni F. Temporal cortex direct current stimulation enhances performance on a visual recognition memory task in Alzheimer disease. J Neurol Neurosurg Psychiatry. 2009 Apr;80(4):444-7.

83 Boggio PS, Ferrucci R, Mameli F, Martins D, Martins O, Vergari M, et al. Prolonged visual memory enhancement after direct current stimulation in Alzheimer's disease. Brain Stimul. 2012 Jul;5(3):223-30.

84 Cotelli M, Manenti R, Brambilla M, Petesi M, Rosini S, Ferrari C, et al. Anodal tDCS during face-name associations memory training in Alzheimer's patients. Front Aging Neurosci. 2014a Mar;6:38.

85 Ferrucci R, Mameli F, Guidi I, Mrakic-Sposta S, Vergari M, Marceglia S, et al. Transcranial direct current stimulation improves recognition memory in Alzheimer disease. Neurology. 2008 Aug;71(7):493-8.

86 Khedr EM, Gamal NF, El-Fetoh NA, Khalifa $\mathrm{H}$, Ahmed EM, Ali AM, et al. A double-blind randomized clinical trial on the efficacy of cortical direct current stimulation for the treatment of Alzheimer's disease. Front Aging Neurosci. 2014 Oct;6:275.
87 Suemoto CK, Apolinario D, Nakamura-Palacios EM, Lopes L, Leite RE, Sales MC, et al. Effects of a non-focal plasticity protocol on apathy in moderate Alzheimer's disease: a randomized, double-blind, sham-controlled trial. Brain Stimul. 2014 Mar-Apr;7(2):30813.

88 Ahmed MA, Darwish ES, Khedr EM, El Serogy YM, Ali AM. Effects of low versus high frequencies of repetitive transcranial magnetic stimulation on cognitive function and cortical excitability in Alzheimer's dementia. J Neurol. 2012 Jan;259(1):83-92.

89 Cotelli M, Manenti R, Cappa SF, Zanetti O, Miniussi C. Transcranial magnetic stimulation improves naming in Alzheimer disease patients at different stages of cognitive decline. Eur J Neurol. 2008 Dec;15(12):1286-92.

90 Cotelli M, Calabria M, Manenti R, Rosini S, Zanetti O, Cappa SF, et al. Improved language performance in Alzheimer disease following brain stimulation. J Neurol Neurosurg Psychiatry. $2011 \mathrm{Jul} ; 82(7): 794-7$.

91 Eliasova I, Anderkova L, Marecek R, Rektorova I. Non-invasive brain stimulation of the right inferior frontal gyrus may improve attention in early Alzheimer's disease: a pilot study. J Neurol Sci. 2014 Nov;346(1-2):31822.

92 Koch G, Bonnì S, Pellicciari MC, Casula EP, Mancini M, Esposito R, et al. Transcranial magnetic stimulation of the precuneus enhances memory and neural activity in prodromal Alzheimer's disease. Neuroimage. 2018 Apr;169:302-11.

93 Rabey JM, Dobronevsky E, Aichenbaum S, Gonen O, Marton RG, Khaigrekht M. Repetitive transcranial magnetic stimulation combined with cognitive training is a safe and effective modality for the treatment of Alzheimer's disease: a randomized, double-blind study. J Neural Transm (Vienna). 2013 May; 120(5):813-9.

94 Rabey JM, Dobronevsky E. Repetitive transcranial magnetic stimulation (rTMS) combined with cognitive training is a safe and effective modality for the treatment of Alzheimer's disease: clinical experience. J Neural Transm (Vienna). 2016 Dec;123(12):1449_ 55.

95 Manenti R, Sandrini M, Gobbi E, Cobelli C Brambilla M, Binetti G, et al. Strengthening of Existing Episodic Memories Through Noninvasive Stimulation of Prefrontal Cortex in Older Adults with Subjective Memory Complaints. Front Aging Neurosci. 2017 Dec;9: 401.

96 Meinzer M, Lindenberg R, Phan MT, Ulm L, Volk C, Flöel A. Transcranial direct current stimulation in mild cognitive impairment: behavioral effects and neural mechanisms. $\mathrm{Al}-$ zheimers Dement. 2015 Sep;11(9):1032-40.
97 Drumond Marra HL, Myczkowski ML, Maia Memória C, Arnaut D, Leite Ribeiro P, Sardinha Mansur CG, et al. Transcranial Magnetic Stimulation to Address Mild Cognitive Impairment in the Elderly: A Randomized Controlled Study. Behav Neurol. 2015;2015:287843.

98 Turriziani P, Smirni D, Zappalà G, Mangano GR, Oliveri M, Cipolotti L. Enhancing memory performance with rTMS in healthy subjects and individuals with Mild Cognitive Impairment: the role of the right dorsolateral prefrontal cortex. Front Hum Neurosci. 2012 Apr;6:62.

99 Cotelli M, Manenti R, Petesi M, Brambilla M, Cosseddu M, Zanetti O, et al. Treatment of primary progressive aphasias by transcranial direct current stimulation combined with language training. J Alzheimers Dis. 2014b;39(4):799-808.

100 Ficek BN, Wang Z, Zhao Y, Webster KT, Desmond JE, Hillis AE, et al. The effect of tDCS on functional connectivity in primary progressive aphasia. Neuroimage Clin. 2018 May; 19:703-15.

101 Gervits F, Ash S, Coslett HB, Rascovsky K, Grossman M, Hamilton R. Transcranial direct current stimulation for the treatment of primary progressive aphasia: an open-label pilot study. Brain Lang. 2016 Nov; 162:3541.

102 Hung J, Bauer A, Grossman M, Hamilton RH, Coslett HB, Reilly J. Semantic Feature Training in Combination with Transcranial Direct Current Stimulation (tDCS) for Progressive Anomia. Front Hum Neurosci. 2017 May;11:253.

103 McConathey EM, White NC, Gervits F, Ash S, Coslett HB, Grossman M, et al. Baseline Performance Predicts tDCS-Mediated Improvements in Language Symptoms in Primary Progressive Aphasia. Front Hum Neurosci. 2017 Jun; 11:347.

104 Roncero C, Kniefel H, Service E, Thiel A, Probst S, Chertkow H. Inferior parietal transcranial direct current stimulation with training improves cognition in anomic $\mathrm{Alz}$ heimer's disease and frontotemporal dementia. Alzheimers Dement (N Y). 2017 Mar;3(2):247-53

105 Teichmann M, Lesoil C, Godard J, Vernet M, Bertrand A, Levy R, et al. Direct current stimulation over the anterior temporal areas boosts semantic processing in primary progressive aphasia. Ann Neurol. 2016 Nov; 80(5):693-707.

106 Tsapkini K, Frangakis C, Gomez Y, Davis C, Hillis AE. Augmentation of spelling therapy with transcranial direct current stimulation in primary progressive aphasia: preliminary results and challenges. Aphasiology. 2014; 28(8-9):1112-30 
107 Huey ED, Probasco JC, Moll J, Stocking J, Ko $\mathrm{MH}, \mathrm{Grafman}$ J, et al. No effect of DC brain polarization on verbal fluency in patients with advanced frontotemporal dementia. Clin Neurophysiol. 2007 Jun;118(6):1417-8.

108 Cotelli M, Adenzato M, Cantoni V, Manenti R, Alberici A, Enrici I, et al. Enhancing theory of mind in behavioural variant frontotemporal dementia with transcranial direct current stimulation. Cogn Affect Behav Neurosci. 2018 Dec;18(6):1065-75.; Epub ahead of print.

109 Antczak J, Kowalska K, Klimkowicz-Mrowiec A, Wach B, Kasprzyk K, Banach M, et al. Repetitive transcranial magnetic stimulation for the treatment of cognitive impairment in frontotemporal dementia: an openlabel pilot study. Neuropsychiatr Dis Treat. 2018 Mar; 14:749-55.

110 André S, Heinrich S, Kayser F, Menzler K, Kesselring J, Khader PH, et al. At-home tDCS of the left dorsolateral prefrontal cortex improves visual short-term memory in mild vascular dementia. J Neurol Sci. 2016 Oct;369:185-90.
111 Bianchi M, Cosseddu M, Cotelli M, Manenti R, Brambilla M, Rizzetti MC, et al. Left parietal cortex transcranial direct current stimulation enhances gesture processing in corticobasal syndrome. Eur J Neurol. 2015 Sep; 22(9):1317-22.

112 Biundo R, Weis L, Fiorenzato E, Gentile G, Giglio M, Schifano R, et al. Double-blind Randomized Trial of tDCS Versus Sham in Parkinson Patients With Mild Cognitive Impairment Receiving Cognitive Training. Brain Stimul. 2015 Nov-Dec;8(6):1223-5.

113 Elder GJ, Firbank MJ, Kumar H, Chatterjee P, Chakraborty T, Dutt A, et al. Effects of transcranial direct current stimulation upon attention and visuoperceptual function in Lewy body dementia: a preliminary study. Int Psychogeriatr. 2016 Feb;28(2):341-7.

114 Manenti R, Brambilla M, Benussi A, Rosini S, Cobelli C, Ferrari C, et al. Mild cognitive impairment in Parkinson's disease is improved by transcranial direct current stimulation combined with physical therapy. Mov Disord. 2016 May;31(5):715-24.

115 Manenti, Bianchi M, Cosseddu M, Brambilla M, Rizzetti C, Padovani A, et al. Anodal transcranial direct current stimulation of parietal cortex enhances action naming in Corticobasal Syndrome. Front Aging Neurosci. 2015 Apr; 7:49.
116 Jessen F, Wolfsgruber S, Wiese B, Bickel H, Mösch E, Kaduszkiewicz H, et al.; German Study on Aging, Cognition and Dementia in Primary Care Patients. AD dementia risk in late MCI, in early MCI, and in subjective memory impairment. Alzheimers Dement. 2014 Jan;10(1):76-83.

117 Margulies DS, Petrides M. Distinct parietal and temporal connectivity profiles of ventrolateral frontal areas involved in language production. J Neurosci. 2013 Oct;33(42): 16846-52.

118 Hachinski V, Iadecola C, Petersen RC, Breteler MM, Nyenhuis DL, Black SE, et al. National Institute of Neurological Disorders and Stroke-Canadian Stroke Network vascular cognitive impairment harmonization standards. Stroke. 2006 Sep;37(9):2220-41.

119 Dirnberger G, Jahanshahi M. Executive dysfunction in Parkinson's disease: a review. J Neuropsychol. 2013 Sep;7(2):193-224.

120 Armstrong MJ, Litvan I, Lang AE, Bak TH, Bhatia KP, Borroni B, et al. Criteria for the diagnosis of corticobasal degeneration. Neurology. 2013 Jan;80(5):496-503. 